\title{
Ground motions in urban \\ Los Angeles from the 2019 \\ Ridgecrest earthquake \\ sequence
}

Earthquake Spectra

202I, Vol. 37(4) 2493-2522

(c) The Author(s) 202।

Article reuse guidelines:

sagepub.com/journals-permissions DOI: $10.1177 / 87552930211003916$

journals.sagepub.com/home/eqs

\author{
Filippos Filippitzis, M.EERI' $(1)$, Monica D Kohler, M.EERI', \\ Thomas H Heaton, M.EERI ${ }^{1,2}$, Robert W Graves, M.EERI ${ }^{3}$, \\ Robert W Clayton ${ }^{2}$, Richard G Guy ${ }^{2}$, Julian J Bunn ${ }^{4}$, and K \\ Mani Chandy ${ }^{5}$
}

\begin{abstract}
We study ground-motion response in urban Los Angeles during the two largest events (M7.I and M6.4) of the 2019 Ridgecrest earthquake sequence using recordings from multiple regional seismic networks as well as a subset of 350 stations from the much denser Community Seismic Network. In the first part of our study, we examine the observed response spectral (pseudo) accelerations for a selection of periods of engineering significance (I, 3, 6, and $8 \mathrm{~s})$. Significant ground-motion amplification is present and reproducible between the two events. For the longer periods, coherent spectral acceleration patterns are visible throughout the Los Angeles Basin, while for the shorter periods, the motions are less spatially coherent. However, coherence is still observable at smaller length scales due to the high spatial density of the measurements. Examining possible correlations of the computed response spectral accelerations with basement depth and Vs30, we find the correlations to be stronger for the longer periods. In the second part of the study, we test the performance of two state-of-the-art methods for estimating ground motions for the largest event of the Ridgecrest earthquake sequence, namely three-dimensional (3D) finitedifference simulations and ground motion prediction equations. For the simulations, we are interested in the performance of the two Southern California Earthquake Center 3D community velocity models (CVM-S and CVM-H). For the ground motion
\end{abstract}

\footnotetext{
'Department of Mechanical and Civil Engineering, Division of Engineering and Applied Science, California Institute of Technology, Pasadena, CA, USA

${ }^{2}$ Seismological Laboratory, Division of Geological and Planetary Sciences, California Institute of Technology, Pasadena, CA, USA

${ }^{3}$ U.S. Geological Survey, Pasadena, CA, USA

${ }^{4}$ The Division of Physics, Mathematics and Astronomy, California Institute of Technology, Pasadena, CA, USA

${ }^{5}$ Department of Computing and Mathematical Sciences, Division of Engineering and Applied Science, California Institute of Technology, Pasadena, CA, USA
}

\section{Corresponding author:}

Filippos Filippitzis, Department of Mechanical and Civil Engineering, Division of Engineering and Applied Science, California Institute of Technology, 1200 E California Blvd, MC 104-44, Pasadena, CA 91 I25, USA.

Email: ffilippi@caltech.edu 


\begin{abstract}
prediction equations, we consider four of the 2014 Next Generation AttenuationWest2 Project equations. For some cases, the methods match the observations reasonably well; however, neither approach is able to reproduce the specific locations of the maximum response spectral accelerations or match the details of the observed amplification patterns.
\end{abstract}

\title{
Keywords
}

Earthquake ground motions, ground motion amplification, community seismic network, Ridgecrest earthquake sequence, simulation predictions, GMPE predictions

Date received: 9 February 202I; accepted: 22 February 2021

\section{Introduction}

The July 2019 Ridgecrest, California, earthquake sequence provides a unique opportunity for a comprehensive study of the resulting ground-motion response in urban Los Angeles. The collected data can potentially be extremely useful for investigating the correlation of the observations with site parameters, as well as for testing ground motion prediction methods. The city of Los Angeles is located about $200 \mathrm{~km}$ from the earthquake epicentral region and did not suffer structural damage; however, because its underlying geology consists of several deep sedimentary basins bounded by mountains, it experienced a wide range of ground-motion amplitudes. Southern California is one of the most densely instrumented areas in the world, with numerous permanent regional strong motion networks. More specifically, our study benefits greatly from the existence of a very dense, permanently installed, community-hosted seismic network - the Community Seismic Network (CSN). Recent instrumentation deployments by the CSN (Clayton et al., 2015, 2020) have led to unprecedented station numbers and density.

The area of urban Los Angeles has been the focus of numerous ground-motion response studies. These ground-motion response studies can be divided into two categories: those studying the recorded data and using them in order to calculate response spectral quantities and other intensity measures and those estimating the intensity measures through model predictions involving full waveform simulation or ground motion prediction equations (GMPEs).

Example works based on recorded ground motions include studies of earthquakes, such as the 1933 Long Beach Earthquake (e.g. Campbell, 1976), the 1971 San Fernando earthquake (e.g. Liu and Heaton, 1984; Rogers et al., 1984), the 1994 Northridge earthquake (e.g. Gao et al., 1996; Harmsen, 1997; Hartzell et al., 1996, 1998), the 2010 El MayorCucapah earthquake (e.g. Hatayama and Kalkan, 2011), and the recent 2019 Ridgecrest earthquake sequence (e.g. Ahdi et al., 2020; Baltzopoulos et al., 2020). Other works analyzed data from non-earthquake sources, for example, from nuclear explosions at the Nevada Test Site (e.g. Rogers et al., 1979; Saikia et al., 1994). In general, these studies found that the long-period ground motions were amplified and the duration of significant shaking was extended in the Los Angeles Basin relative to sites outside the basin.

In addition to using measured data, other studies attempt to simulate the ground motions or provide intensity measure estimates through model predictions. Some examples include calculations of finite-difference seismograms for the 1971 San Fernando earthquake from Vidale and Helmberger (1988) and the use of two-dimensional (2D) finitedifference ground-motion simulations for the 1994 Northridge earthquake from Graves 
et al. (1998). In later years, three-dimensional (3D) numerical simulations saw increased use. Examples include works for the 1992 Landers earthquake (e.g. Wald and Graves, 1998), the 1994 Northridge earthquake (e.g. Olsen et al., 2003), the 2001 Hollywood and the 2002 Yorba Linda earthquakes (e.g. Komatitsch et al., 2004), or scenario earthquakes (e.g. Olsen et al., 1995). State-of-the-art simulations model wave propagation using realistic models of the seismic fault rupture, the propagation path, and 3D velocity models. Some examples of recent studies include work on source complexity (e.g. Graves and Pitarka, 2016; Rodgers et al., 2018; Shi and Day, 2013) and fault zone plasticity (e.g. Roten et al., 2017; Wollherr et al., 2018), as well as work on attenuation models (e.g. Withers et al., 2015, 2019). The most commonly used regional seismic velocity models for this purpose are the two Southern California Earthquake Center (SCEC) community velocity models (CVMs): CVM-S (Kohler et al., 2003; Lee et al., 2014b; Magistrale et al., 2000) and CVM-H (Shaw et al., 2015; Süss and Shaw, 2003). The differences in the two CVMs lead to different simulation results and performance (Lee et al., 2014a; Taborda and Bielak, 2013, 2014). Comparing the performance between the different CVMs, the recent study by Taborda et al. (2016) indicated the CVM-S model (version CVM-S4.26) to be performing the best for the majority of the examined events.

GMPEs are empirical equations frequently used in seismic hazard applications to provide estimates of the response spectral acceleration, peak ground acceleration, and peak ground velocity as a function of predictor variables such as earthquake magnitude, site-tosource distance, and site parameters (Petersen et al., 2008). The most frequently used GMPEs in the Western United States are the five that were developed as part of the Next Generation Attenuation-West2 (NGA-West2) project (Bozorgnia et al., 2014). Similar to the CVMs, the different model derivations result in broad differences in the GMPE predictions (Gregor et al., 2014).

This study focuses on characterizing the patterns in the recorded ground-motion response that occurred in urban Los Angeles as a result of the two largest Ridgecrest earthquakes, the M7.1 main shock and M6.4 foreshock. We make use of response pseudospectral acceleration intensity measures (also referred to as spectral acceleration) in order to address two main objectives. Our first objective involves applying spectral acceleration computations to measured data. We show that the ground-motion patterns in the computed spectral accelerations from seismic network recordings of the M7.1 and M6.4 earthquakes are similar between the two events, and we examine correlations with two common site parameters: Vs30 (travel-time averaged shear-wave velocity in the top $30 \mathrm{~m}$ ) and the depth-to-basement. The second objective focuses on assessing the capabilities of different ways of predicting the spectral acceleration observed for the largest (M7.1) event. We study two common methods for predicting ground motion: 3D finite-difference simulations and GMPEs. We examine the performance of the two methods by constructing maps of their spectral acceleration predictions, as well as along a profile through the Los Angeles Basin.

\section{Ridgecrest earthquake sequence}

The July 2019 Ridgecrest earthquake sequence occurred northeast of the town of Ridgecrest, CA (Figure 1a), along two major fault zones. The sequence consisted of seven moderate-to-strong events (magnitude greater than 5.0), and over a 100 events with magnitude greater than 4.0 (Andrews, 2019; Hauksson et al., 2020). In this study, we consider the two largest events of the sequence - the M7.1 main shock and the M6.4 foreshock. The M7.1 main shock took place on 6 July 2019 at 03:19 UTC (5 July 20:19 local time) 

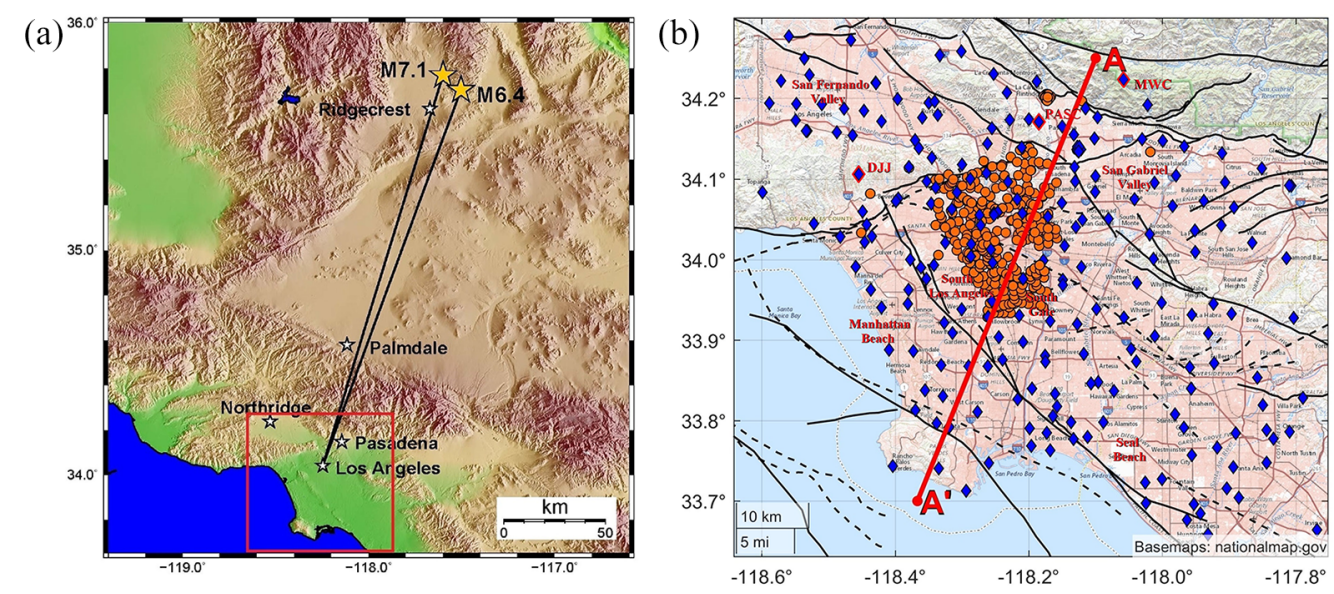

Figure I. Maps of the region. (a) Earthquake epicenters and terrain. Red rectangle: the area of urban Los Angeles under consideration, magnified on the following figures. Black lines: the shortest source-toreceiver path corresponding to a distance of $\sim 200 \mathrm{~km}$. (b) Station and fault locations. Orange circles: CSN network. Blue diamonds: SCSN and CSMIP networks. Solid black lines: fault traces. Dashed black lines: blind fault surface projection. Profile $A-A^{\prime}$ is marked by the red line.

with a hypocenter of $35.770^{\circ} \mathrm{N}, 117.599^{\circ} \mathrm{W}$ and depth of about $8 \mathrm{~km}$. The second strongest event of the sequence was the M6.4 earthquake that occurred approximately $34 \mathrm{~h}$ before the M7.1 event, on 4 July 2019 at 17:33 UTC (4 July 10:33 local time). Its epicenter was located $11 \mathrm{~km}$ southeast of the main event's epicenter (epicenter location: $35.705^{\circ} \mathrm{N}$ and $117.504^{\circ} \mathrm{W}$ ), with a hypocentral depth of about $10 \mathrm{~km}$. The shaking from the two events was widely felt throughout California and was well-recorded by the numerous seismic arrays operating in southern California. In particular, the city of Los Angeles, located about $200 \mathrm{~km}$ from the event epicenters (Figure 1a) experienced light-to-moderate ground shaking; however, the long-period shaking was strong enough that residents in the downtown high-rises reported experiencing vertigo (Lin, 2019).

\section{Data and processing}

Acceleration time series from the two events form the basis of this study. We consider ground-level stations from the following three sources: (1) the CSN, (2) the Southern California Seismic Network (SCSN) (California Institute of Technology and United States Geological Survey Pasadena, 1926), and (3) the California Strong Motion Instrumentation Program (CSMIP). The CSN provided data from 350 stations, and SCSN and CSMIP provided about 200 additional stations in our region of interest (Figure 1b). The high station density visible in the northern part of the Los Angeles Basin is due to the CSN deployment which spans an approximately $30 \mathrm{~km}$ by $30 \mathrm{~km}$ area, with an average station spacing of about $0.5 \mathrm{~km}$. The SCSN and CSMIP stations are an order of magnitude more distant from one another with approximate station spacing of about $4 \mathrm{~km}$.

The CSN and SCSN data were processed by applying a non-causal fourth-order bandpass Butterworth filter for frequencies between 0.07 and $23 \mathrm{~Hz}$. The cutoff frequencies and order of the filter were selected to be similar to the ones applied to the already-processed CSMIP V2 accelerograms. The overall data quality for all three networks for both events 
is high with good site-to-site coherence for neighboring stations in similar geological settings. The performance of the CSN MEMS-based sensors during the earthquakes was on par with the SCSN and CSMIP sensors and is discussed in more detail in Clayton et al. (2020). A comparison of the recordings and the resulting pseudo-acceleration response spectra between a CSN accelerometer and a regional network accelerometer at the same site is shown in Figure $\mathrm{S} 1$ in the supplementary material.

\section{Methodology}

We compute the response pseudo-spectral acceleration (Chopra, 2011; Housner, 1941) at each station by applying the recorded ground acceleration as input to a linear singledegree-of-freedom (SDoF) oscillator with natural period $T$ and damping ratio $\zeta$. Solving for the two available horizontal inputs (i.e. the ground accelerations in the geographical E-W and N-S directions) yields the oscillator displacements in the two horizontal directions: $u_{x}(t)$ and $u_{y}(t)$. We define the response pseudo-spectral acceleration ("SA") as:

$$
S A(T, \zeta)=\omega^{2} \max _{t}(u(t))
$$

where $u(t)$ is the Euclidean norm of the horizontal displacement $\left(u(t)=\left(u_{x}(t)^{2}+u_{y}(t)^{2}\right)^{1 / 2}\right)$ and the subscript $t$ indicates that we are looking for the maximum with respect to time. We also associate a geographical direction to this SA that is the direction of the vector $\boldsymbol{u}\left(t_{m}\right)=u_{x}\left(t_{m}\right) \boldsymbol{e}_{\boldsymbol{x}}+u_{y}\left(t_{m}\right) \boldsymbol{e}_{\boldsymbol{y}}$ at time $t_{m}$ when $u(t)$ attains its maximum value, defined by the angle:

$$
\varphi=\arctan \left(\frac{u_{y}\left(t_{m}\right)}{u_{x}\left(t_{m}\right)}\right)
$$

It can be shown (see Appendix 1) that the SA is equivalent to RotD100, the maximum spectral acceleration over all rotation angles (Boore, 2010). Furthermore, the direction of the SA (Equation 2) is equal to the rotation angle for which the maximum spectral acceleration occurs. Since Equation 1 does not require an iteration over all (non-redundant) rotation angles, the calculation of SA is computationally more efficient. Moreover, since the recommended procedure for calculating RotD100 suggests 1 degree angle increments, calculating SA is more accurate.

In the simulation and GMPE comparison sections of the paper, we make use of RotD50, the median spectral acceleration over all rotation angles (Boore, 2010), also defined in Appendix 1. The RotD50 is calculated for the data and the models. A rotation over all angles is required for this computation and 1 degree angle increments are used.

\section{Spectral acceleration results}

Figure 2 shows the SAs computed for the M7.1 and M6.4 Ridgecrest earthquakes at four natural (vibration) periods $T$ for the SDoF oscillator: 1, 3, 6, and $8 \mathrm{~s}$ for stations from all three seismic networks (CSN, SCSN, and CSMIP) in the Los Angeles basin region. These four periods are representative of the fundamental periods of many of the structural systems present in the region, since the fundamental periods for low- and mid-rise buildings are close to 1 and $3 \mathrm{~s}$, while for high-rises, large-diameter storage tanks, or long-span bridges, 6 and $8 \mathrm{~s}$ are more appropriate. We use 5\% damping ratio for comparison with the GMPE predictions which also use $5 \%$ damping. However, we believe that a $2 \%$ 

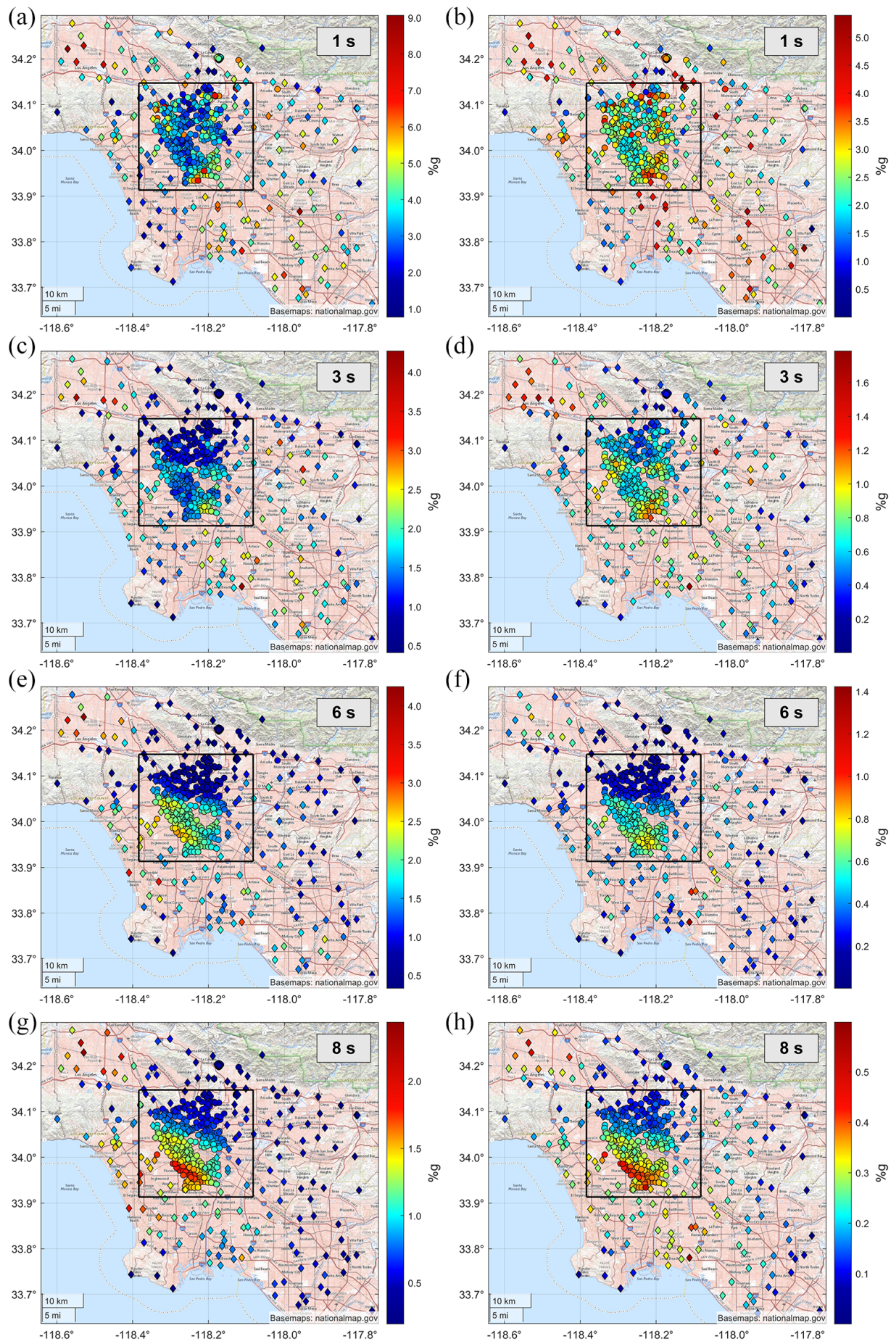

Figure 2. Pseudo-spectral acceleration (SA) maps. Left column: M7.I earthquake. Right column: M6.4 earthquake. (a and b) $T=1 \mathrm{~s}$, (c and d) $T=3 \mathrm{~s}$, (e and $\mathrm{f}) T=6 \mathrm{~s}$, and $(\mathrm{g}$ and $\mathrm{h}$ ) $T=8 \mathrm{~s}$. Damping ratio $=5 \%$. Circles: CSN stations, Diamonds: SCSN and CSMIP stations. Black rectangle: Area magnified in Figure 3. Note varying colorbar amplitude scales. 
damping ratio is more appropriate for the longer $(\geqslant 6 s)$ periods. Strains are known to decay rapidly with increasing distance from the fault (Hays, 1984). Since the events were distant and the peak ground velocities recorded in the Los Angeles area were small, the response is expected to be in the linear regime. For a mid- or high-rise structural system linearly responding at its dominant mode, a $2 \%$ damping ratio is found to be a more suitable value (Cruz and Miranda, 2017). We include maps using 2\% damping ratio in the supplementary material (Figures S2 and S3), and in a separate study that focuses on longperiod site amplification and its effects on high-rises (Kohler et al., 2020).

It is evident from Figure 2 that the ground-motion response varies greatly across the Los Angeles region, with SA values generally smaller at hard-rock sites (e.g. in the San Rafael Hills or Mt. Wilson), but much larger (as much as ten times larger at $T=6 \mathrm{~s}$ ) for sites in the basin. At $T=1 \mathrm{~s}$, the SA varies significantly over short distances with no pervasive patterns and with local maxima appearing in multiple locations. At $T=3 \mathrm{~s}$, more coherent behavior can be observed, with larger SA values appearing in the San Fernando Valley, the San Gabriel Valley, and in the central (e.g. South Gate) and southern (e.g. Long Beach) Los Angeles Basin. At the longer periods ( $T=6$ and $8 \mathrm{~s})$, pervasive coherent behavior is now evident, with maxima located in the San Fernando Valley, and in the west (e.g. Manhattan Beach), central (South Los Angeles), and south (e.g. north of Seal Beach) Los Angeles Basin (the above named locations are noted in Figure 1b).

Figure 3 presents a detail of Figure 2 focused on the area with the denser CSN instrumentation. For the longer periods, coherent patterns are present throughout the region with the SA amplitude gradually varying, but for the shorter periods, the spatial complexity of the SA patterns increases significantly. The dense CSN instrumentation allows us to see pockets of SA amplification, varying over length scales of $1-2 \mathrm{~km}$, which would go undetected using only data from the sparser SCSN and CSMIP networks. We provide RotD50 maps equivalent to Figures 2 and 3 in the supplementary material (Figures S4 and S5).

The directions associated with the maximum SA values are shown in Figure 4. The patterns in the directions further emphasize the observations of coherent behavior for the longer periods. At $T=8 \mathrm{~s}$, the SAs have coherent directions across the entire Los Angeles Basin. Considering waves with 8-s period propagating at a shear-wave velocity of $2.5 \mathrm{~km} / \mathrm{s}$, one gets a wavelength of about $20 \mathrm{~km}$; the wavelength goes down to only $2.5 \mathrm{~km}$ for a $1-\mathrm{s}$ period. In reality, the wavelengths associated with the 1-s period energy are even shorter since they are more sensitive to the lower velocity, near-surface material. Taking into account this decrease in the wavelengths and the average station spacing, it is not surprising that the coherence breaks down at the shortest periods. For the shortest periods, coherence in the directions can still be observed at smaller length scales in specific areas (Figure S6 in the supplementary material) with the help of the denser CSN.

Figure 5 shows the spatial correlations using the Ridgecrest M7.1 earthquake recorded on the CSN network. The correlations are calculated by cross-correlating the stations pair-wise over a time window that includes all of the main coda of the event. The data are narrow-band filtered with a bandwidth of $0.5 \mathrm{~Hz}$, centered on the particular period, and the zero-lag of the correlation is computed for all pairs with the same spatial separation. This is repeated for all station pairs resulting in approximately 500 composites for each distance-frequency point. We do not include estimates at distances of 0.1 and $0.2 \mathrm{~km}$ since very few stations have these separations. The correlation distance is defined to be at correlation level 0.5 . At $T=1 \mathrm{~s}$, the correlation distance is found to be only $0.3 \mathrm{~km}$, while at 

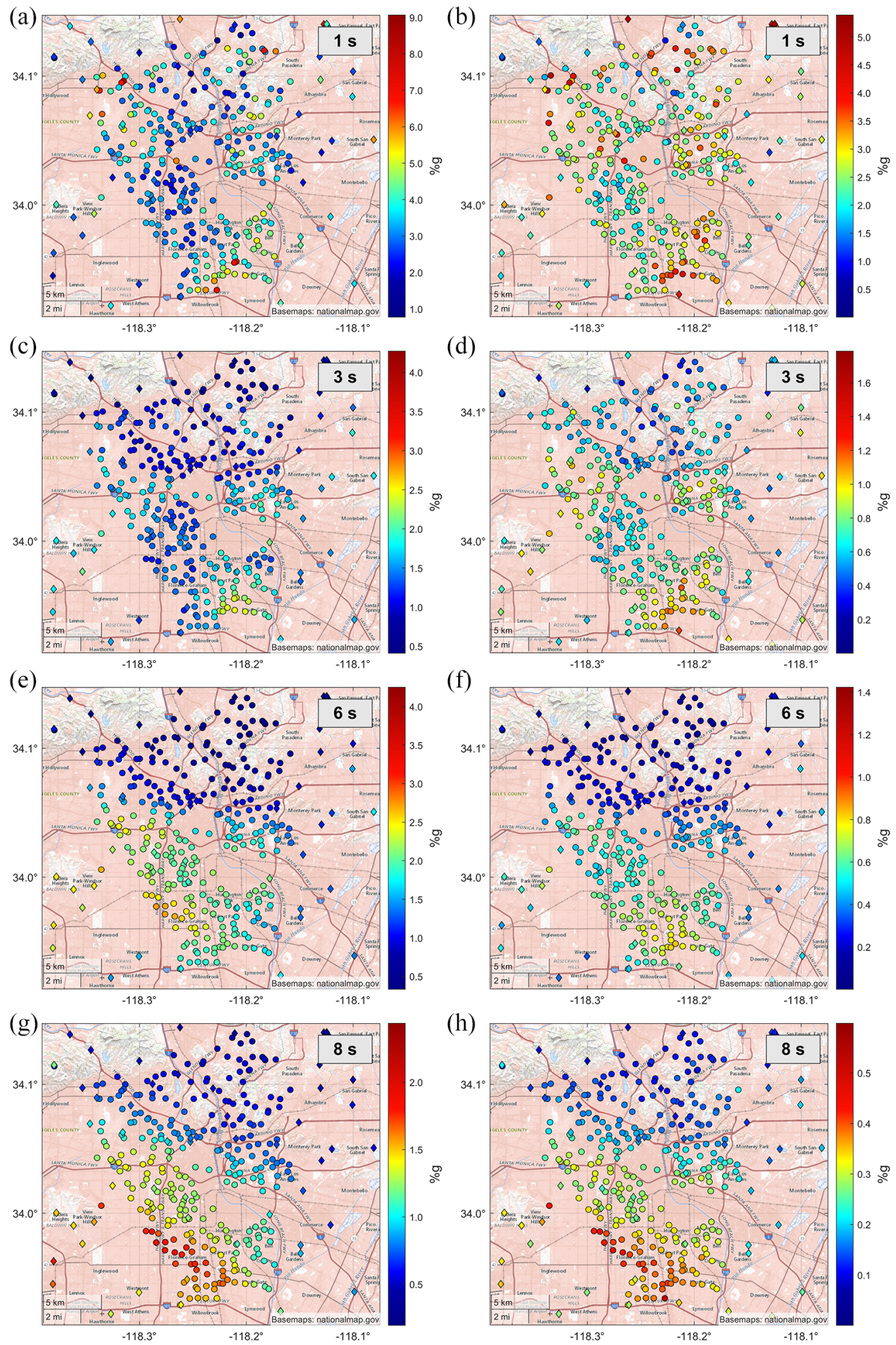

Figure 3. SA maps showing detail in the region marked by the black rectangle in Figure 2. Left column: M7.I earthquake. Right column: M6.4 earthquake. ( $a$ and $b$ ) $T=I \mathrm{~s}$, (c and d) $T=3 \mathrm{~s}$, (e and $\mathrm{f}$ ) $\mathrm{T}=6 \mathrm{~s}$, and $(\mathrm{g}$ and $\mathrm{h}) \mathrm{T}=8 \mathrm{~s}$. Damping ratio=5\%. Circles: CSN stations, Diamonds: SCSN \& CSMIP stations. Note varying colorbar amplitude scales. 

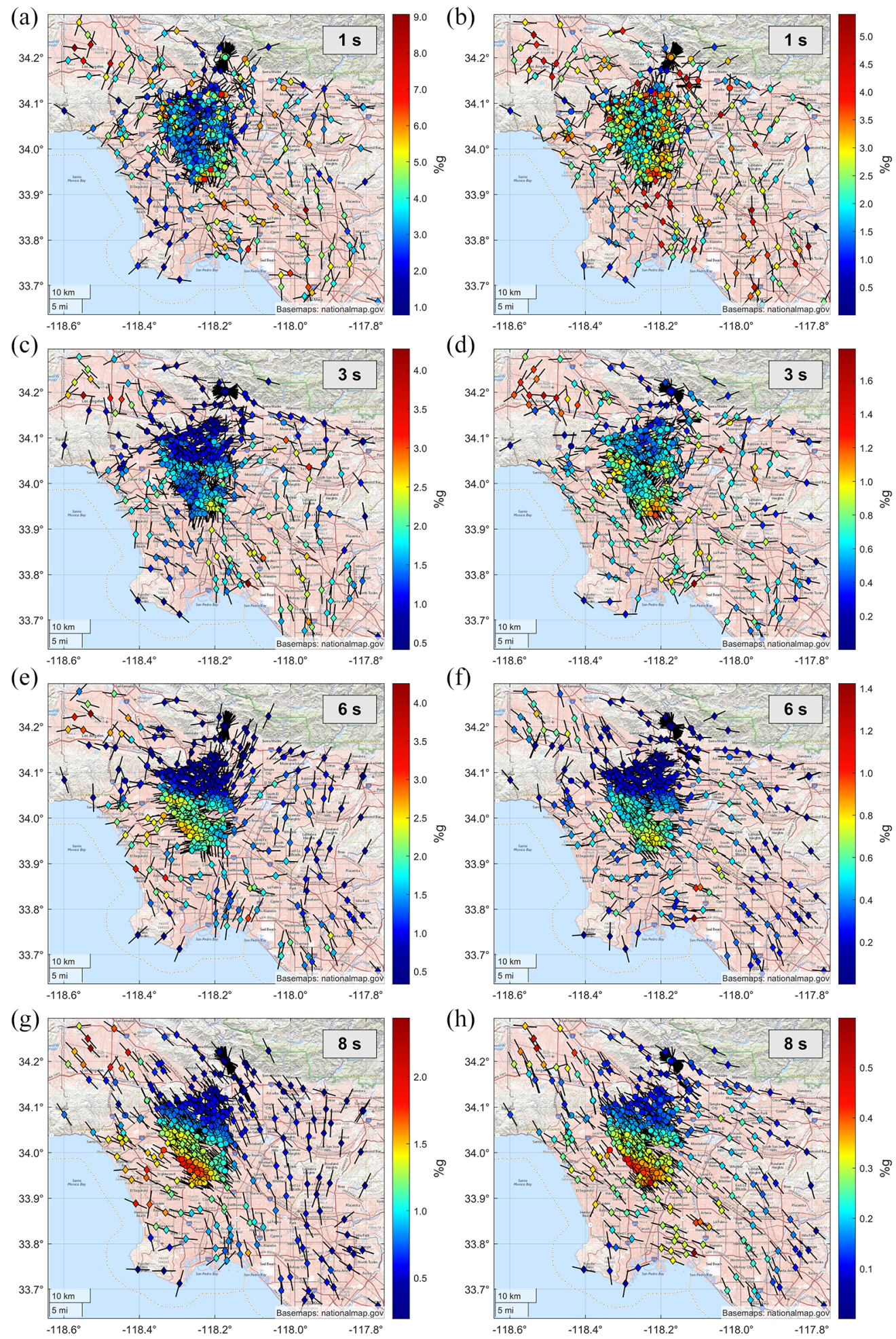

Figure 4. SA direction maps. Left column: M7.I earthquake. Right column: M6.4 earthquake. (a and b) $\mathrm{T}=\mathrm{I} \mathrm{s}$, (c and d) $\mathrm{T}=3 \mathrm{~s}$, (e and $\mathrm{f}) \mathrm{T}=6 \mathrm{~s}$, and $(\mathrm{g}$ and $\mathrm{h}) \mathrm{T}=8 \mathrm{~s}$. Damping ratio=5\%. Circles: CSN stations, Diamonds: SCSN \& CSMIP stations. Black lines: indicate the SA directions. Note varying colorbar amplitude scales. 


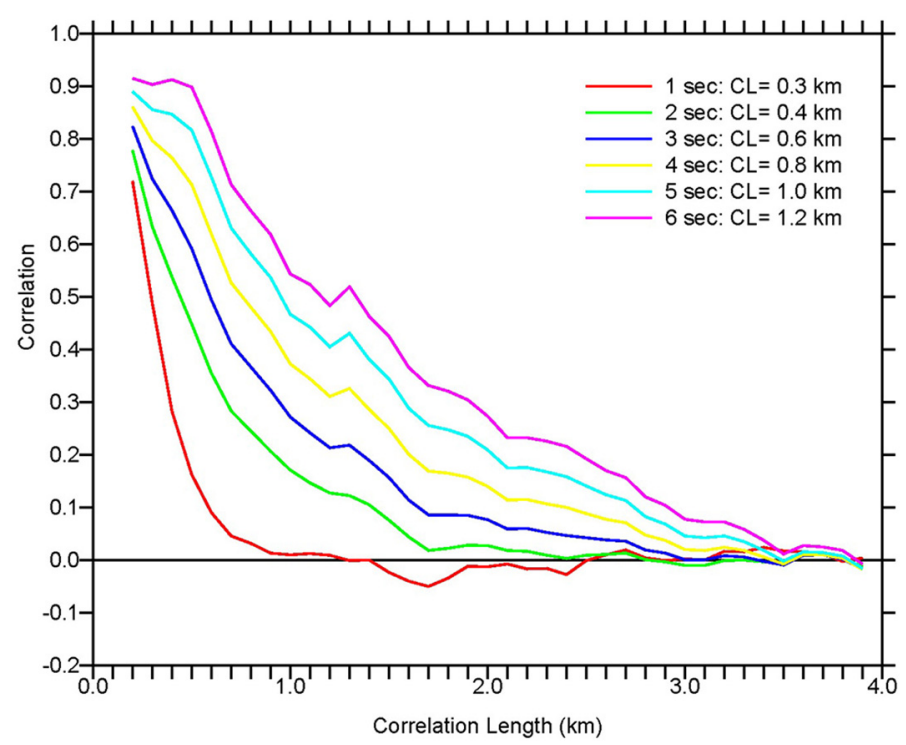

Figure 5. Spatial correlations computed from the Ridgecrest M7.I earthquake CSN recordings plotted versus correlation length, for $T=1,2,3,4,5$, and $6 \mathrm{~s}$.

$T=6 \mathrm{~s}$ the correlation distance is $1.2 \mathrm{~km}$. This is consistent with our previous observations from the maps in Figures 2 and 4. That is, for the longer periods, there is coherence of the observed SA over large length scales, while for the shorter periods, the spatial complexity of the SA increases with coherence over smaller length scales.

The SA results are for the most part reproducible between the two earthquakes. At $T=1,3$, and $8 \mathrm{~s}$, the areas of the maximum SA are consistent between the two events (Figure 2a to h). The results for the two events are slightly different at $T=6 \mathrm{~s}$ where for the Los Angeles Basin the maximum SA appears toward the west coastline (e.g. Manhattan Beach and South Los Angeles) for the M7.1, but more to the east (e.g. South Gate), for the M6.4 event (Figure 2e and f).

Even though the SA values are generally smaller for the M6.4 event as expected, the SA ratios between a site in the deeper Los Angeles Basin and a hard-rock site are similar between the two events. In Figure S7 in the supplementary material, we provide maps of the ratios of the SA for each site relative to the average of three SCSN seismic stations located on hard-rock sites in greater Los Angeles. The three stations selected are PASC located in the hills on the western boundary of the San Gabriel Valley, DJJ at Stone Canyon Reservoir in the eastern Santa Monica Mountains, and MWC at Mount Wilson Observatory in the San Gabriel Mountains (the locations are marked in Figure 1b). At all periods, the range of the SA ratio values is comparable between the two events (e.g. about (0-6) for both events at $T=3 \mathrm{~s}$ ). The SA ratio maps for the two events look similar, especially at the longer periods (nearly indistinguishable at $8 \mathrm{~s}$ ).

As another approach to quantifying the correlation between the data from the two events, Figure 6 shows SA values for all stations that recorded both events on a log-log scale. The linear scale plots are provided in the supplementary material in Figure S8. It is apparent that an overall good correlation exists and that the observed SAs are consistent 

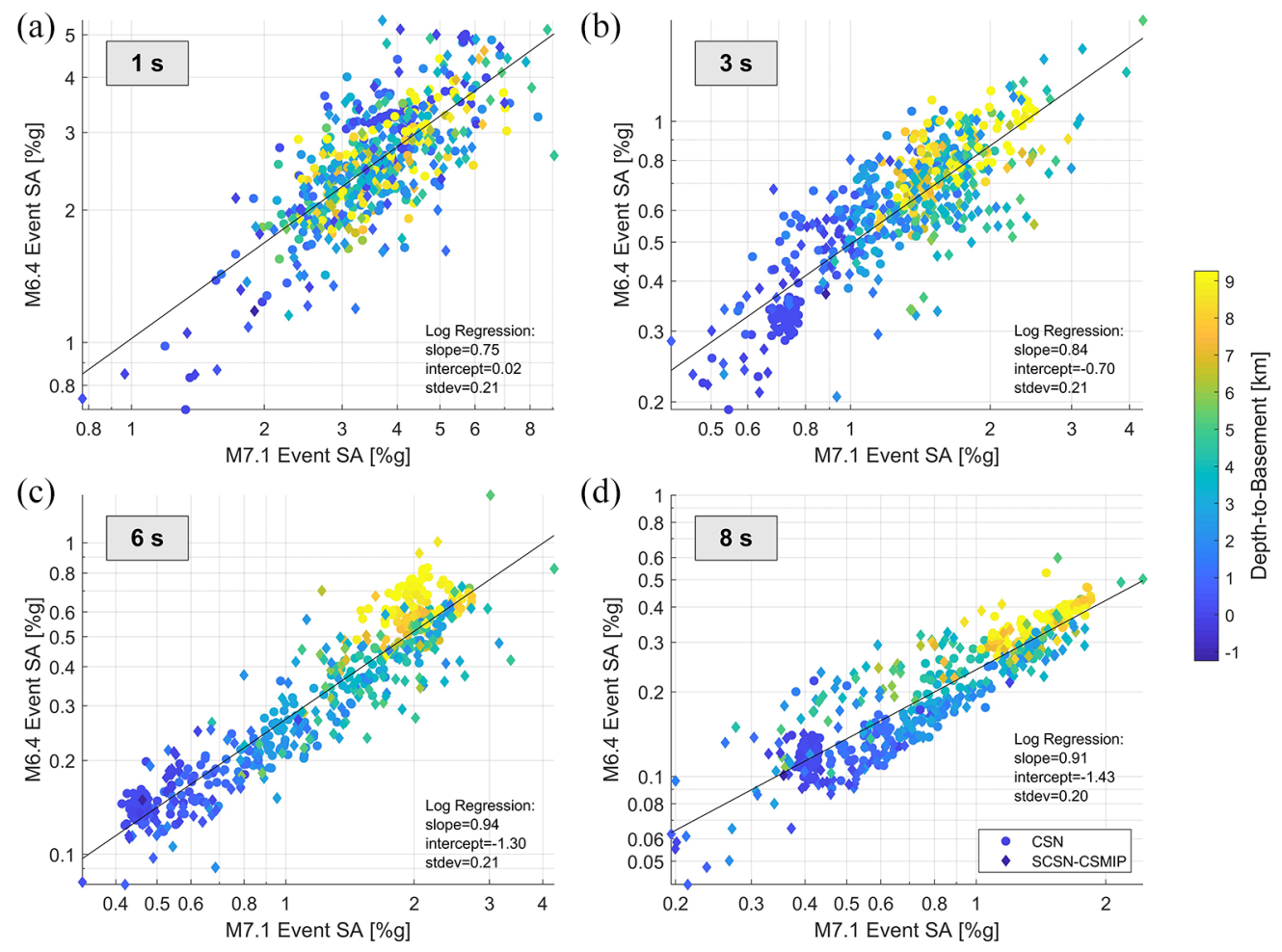

Figure 6. SA correlation between the two earthquakes-logarithmic scale. (a) $T=1 \mathrm{~s}$, (b) $T=3 \mathrm{~s}$, (c) $T=6 \mathrm{~s}$, and (d) $T=8 \mathrm{~s}$. Damping ratio $=5 \%$. Circles: CSN stations, Diamonds: SCSN and CSMIP stations. The colormap displays the depth-to-basement at each station. The solid line shows the leastsquares (LS) regression fit performed in log-log scale. The slope and intercept of the LS regression line, and the standard deviation of the log values are provided in each subplot.

between the two events. To quantify the degree of correlation, we calculate the leastsquares (LS) regression line for the natural logarithms of the SA values. Two statistical measures are computed: Pearson's correlation coefficient $(r)$ and the $p$-value $(p)$ with the null hypothesis being that the slope of the LS regression line is zero (Lee et al., 2000). We find $r=0.75,0.84,0.94$, and 0.91 for $T=1,3,6$, and $8 \mathrm{~s}$, respectively. As the correlation coefficient approaches +1 , the two variables have a stronger positive correlation. The SA correlation between the two events is stronger for longer periods, independent of the depth-to-basement at the station (shown by the color map in Figure 6). The $p$-values are $p<0.001$ for all four periods, which is an indication that the correlation is statistically significant.

\section{Correlation with site parameters}

It is common practice in many engineering applications to estimate the ground-motion response through empirical correlations with site parameters. The site parameters that are most commonly used are related to basement depth and Vs30. Ground-motion amplification has been shown to increase at longer periods with increasing basement depth (e.g. Liu and Heaton, 1984), which is usually obtained by well penetration, seismic or gravity data 
(e.g. Shaw et al., 2015). Vs30 data, used as a proxy for different local soil properties, take into account site-specific measurements, as well as surface geology and topographic gradient (e.g. Thompson et al., 2014). In both cases, the resolution of these parameters is limited by the density and quality of the measurements.

We calculate the depth-to-basement and Vs30 for each site from grid values using a triangulation-based linear interpolation. The depth-to-basement grid values are from Shaw et al. (2015). The depth-to-basement values correspond to the depth to crystalline rock/basement. Negative values correspond to surface outcrop (Figure 7a). The Vs30 grid values are from Thompson (2018) (Figure 7b) and account for constraints from multiple sources (site-specific measurements, surface geology, and topographic gradient). As discussed in Brown et al. (2002), there are a number of advantages to using slowness rather than velocity; hence in the following, we will be considering the shear-wave slowness in the top $30 \mathrm{~m}$, defined as $\mathrm{Ss} 30=1 / \mathrm{Vs} 30$. This also allows us to better focus on the low Vs30 regions.

Plotting the depth-to-basement against the Ss30 (and Vs30) values of each station, a statistically significant correlation appears (Figure 7c). Sediments are highly correlated with basins and the Vs30 is affected by the existence of such sediments. In Figure 7c, one can see this built-in correlation between the Vs30 and the deeper structures. Another interesting feature of Figure 7c is the banded behavior of the Vs30 values. This is likely due to the fact that in the absence of site-specific measurements, the Vs30 values account for surface geology and topographic gradient (Thompson et al., 2014). The smoothness of the Vs30 dataset in combination with the high spatial density of the seismic networks results in many stations having exactly the same Vs30 value even if their underlying soil conditions are not exactly the same.

Figure 8 shows the observed SA for each station against its corresponding depth-tobasement value on a log-log scale. When looking at the logarithms, we only consider positive depth-to-basement values. We include the linear scale plots in the supplementary material in Figure S9. For $T=1 \mathrm{~s}$, there appears to be no correlation between SA and depth-to-basement. However, for the longer periods, a correlation appears and sites with larger depth-to-basement have, on average, larger SA. However, it is not always the case that the largest SA corresponds to the areas of the deepest basement depth. Similar to what was done previously, in order to quantitatively assess the correlations, we compute an LS regression fit on the natural logarithm of the values and calculate the correlation coefficients $(r)$ and the $p$-values $(p)$. We find $r=0.05,0.76,0.85$, and 0.74 for $T=1,3$, 6 , and $8 \mathrm{~s}$, respectively. The $p$-values are $p=0.22$ for $T=1 \mathrm{~s}$ and $p<0.001$ for $T=3$, 6 , and $8 \mathrm{~s}$. The $p$-values confirm that the correlation is statistically significant for the longer periods. The correlation is the strongest at $6 \mathrm{~s}$.

Examining other depth-related parameters yields similar results. We consider the depths to shear-wave velocity $=1.0 \mathrm{~km} / \mathrm{s}(\mathrm{Z1} .0)$ as well as the depth to shear-wave velocity $=$ $2.5 \mathrm{~km} / \mathrm{s}(\mathrm{Z} 2.5)$ using both CVMs (CVM-S and CVM-H). The observed SA correlate with the Z1.0 and Z2.5 depths in a similar way. There is either no or weak correlation for the $T=1 \mathrm{~s}$ period, while a correlation exists and gets stronger for the longer periods. Logarithmic plots showing the correlation with the Z1.0 and Z2.5 depths are included in the supplementary material in Figures S11 to S14. The computed correlation coefficients $(r)$ and the $p$-values $(p)$ are provided in the supplement in Table S1.

Figure 9 displays the correlation between every station's observed SA and its corresponding Ss30 on a log-log scale. The linear scale plots are included in the supplementary 

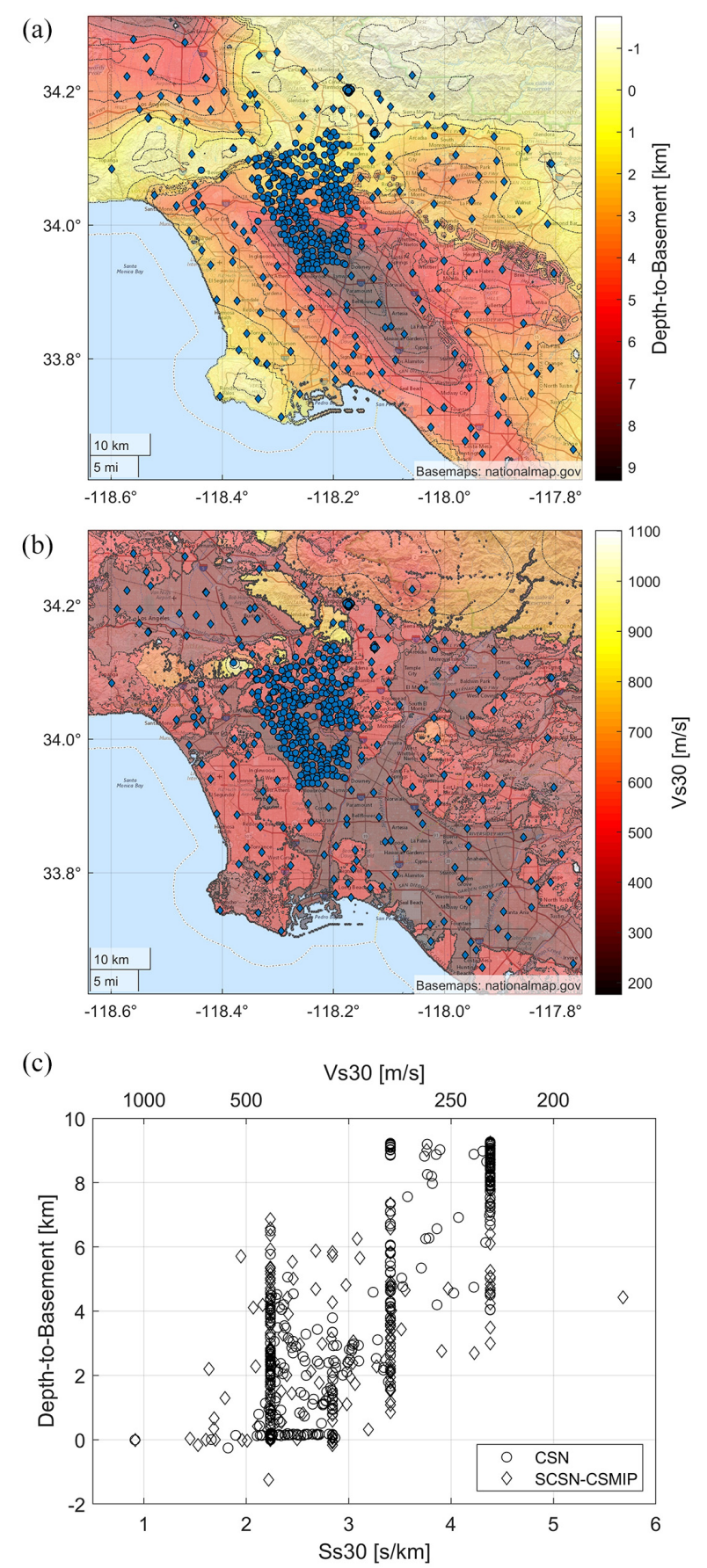

Figure 7. Site parameter plots. (a) Sensor locations (blue circles and diamonds) plotted on top of contoured depth-to-basement (Shaw et al., 2015). (b) Sensor locations (blue circles and diamonds) plotted on top of contoured Vs30 (Thompson, 2018). (c) Scatter plot of the depth-to-basement plotted against Ss30 and Vs30 at the station locations. Circles: CSN stations, Diamonds: SCSN and CSMIP stations. Negative depth-to-basement corresponds to positive basement elevation (i.e. surface outcrop). Depth-toBasement contours are marked at I km intervals. Vs30 contours are marked at $100 \mathrm{~m} / \mathrm{s}$ intervals. 

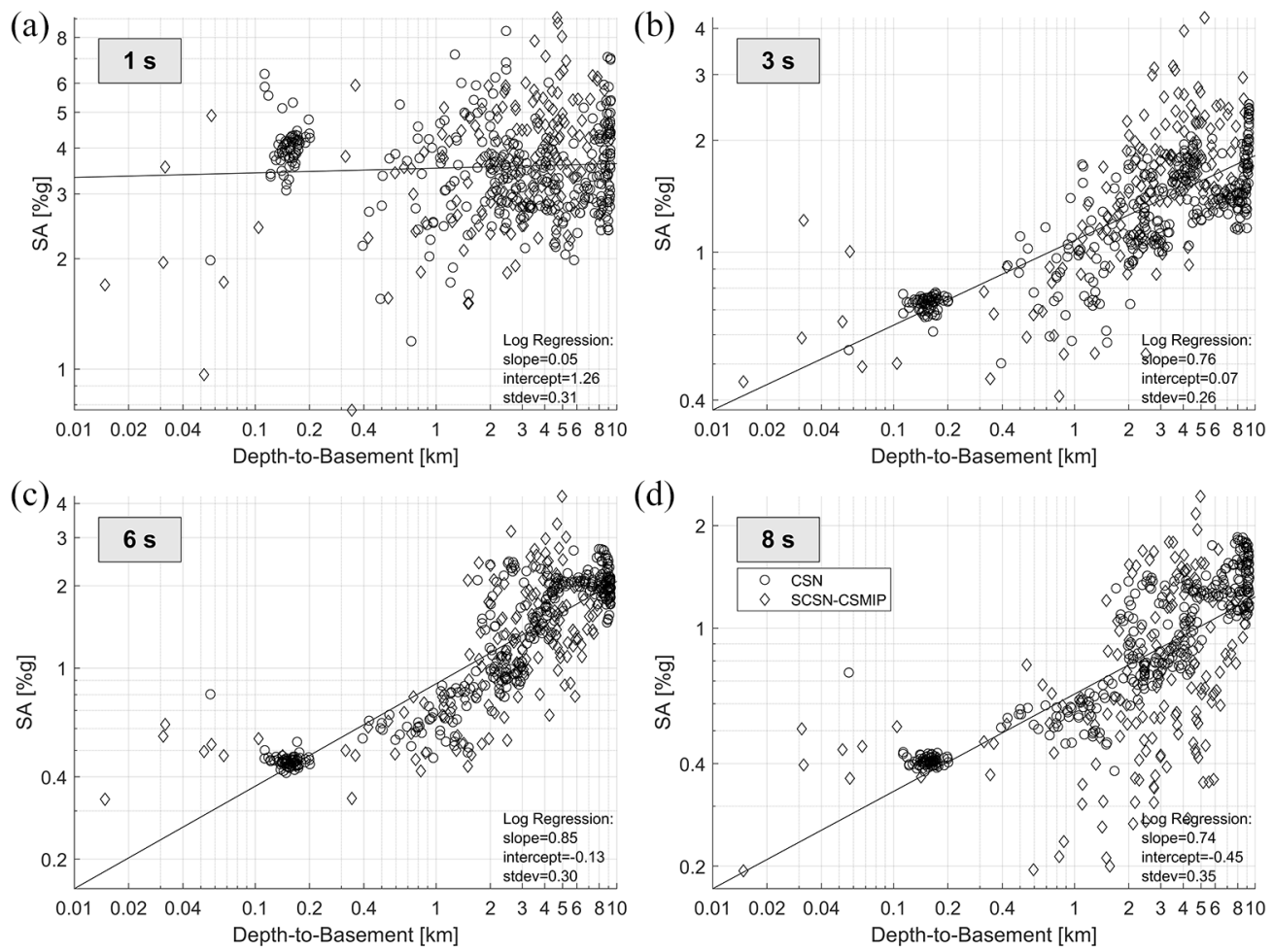

Figure 8. SA correlation with depth-to-basement for the M7.I earthquake-logarithmic scale. (a) $T=1 \mathrm{~s}$, (b) $T=3 \mathrm{~s}$, (c) $T=6 \mathrm{~s}$, and (d) $T=8 \mathrm{~s}$. Damping ratio $=5 \%$. Circles: CSN stations, Diamonds: SCSN and CSMIP stations. The solid line shows the least-squares (LS) regression fit performed in log-log scale. The slope and intercept of the LS regression line, and the standard deviation of the log values are provided in each subplot.

material in Figure S10. A main feature of Figure 9 is the banded pattern of the Ss30, discussed previously for Figure 7c. This pattern makes it difficult to visually observe any correlation between SA and Ss30, but the statistical measures $r$ and $p$ suggest that there exists a weak but statistically significant correlation. The correlation is weak for $T=1 \mathrm{~s}$ and gets stronger for the longer periods. The correlation is the strongest for $T=6 \mathrm{~s}$. Examining the LS regression fit on the natural logarithm of the values, we find $r=0.15$, $0.46,0.52$, and 0.45 for $T=1,3,6$, and $8 \mathrm{~s}$, respectively. The $p$-values are $p<0.001$ for all periods.

The correlation of the observations with Vs30 was expected to be stronger for the shorter periods. Vs30 and SA have been found to have a strong correlation at $T=1 \mathrm{~s}$ in empirical ground-motion data sets, such as the NGA-W2 data set (Ancheta et al., 2014). The repeated Vs30 values and banded Vs30 behavior for the spatially dense CSN stations, also discussed in Figure 7c, likely obscures the Vs30 scaling at the shorter length scales (i.e. shorter periods). The observed stronger correlation between SA and Vs30 for the longer periods might also come as a surprise, due to the fact that from its definition the Vs30 measure only accounts for the local, near-surface conditions. These correlation trends likely result from the inherent correlation of Vs30 with basement depth in the Los Angeles region, as demonstrated in Figure 7c. At the longer periods, the correlation between SA 

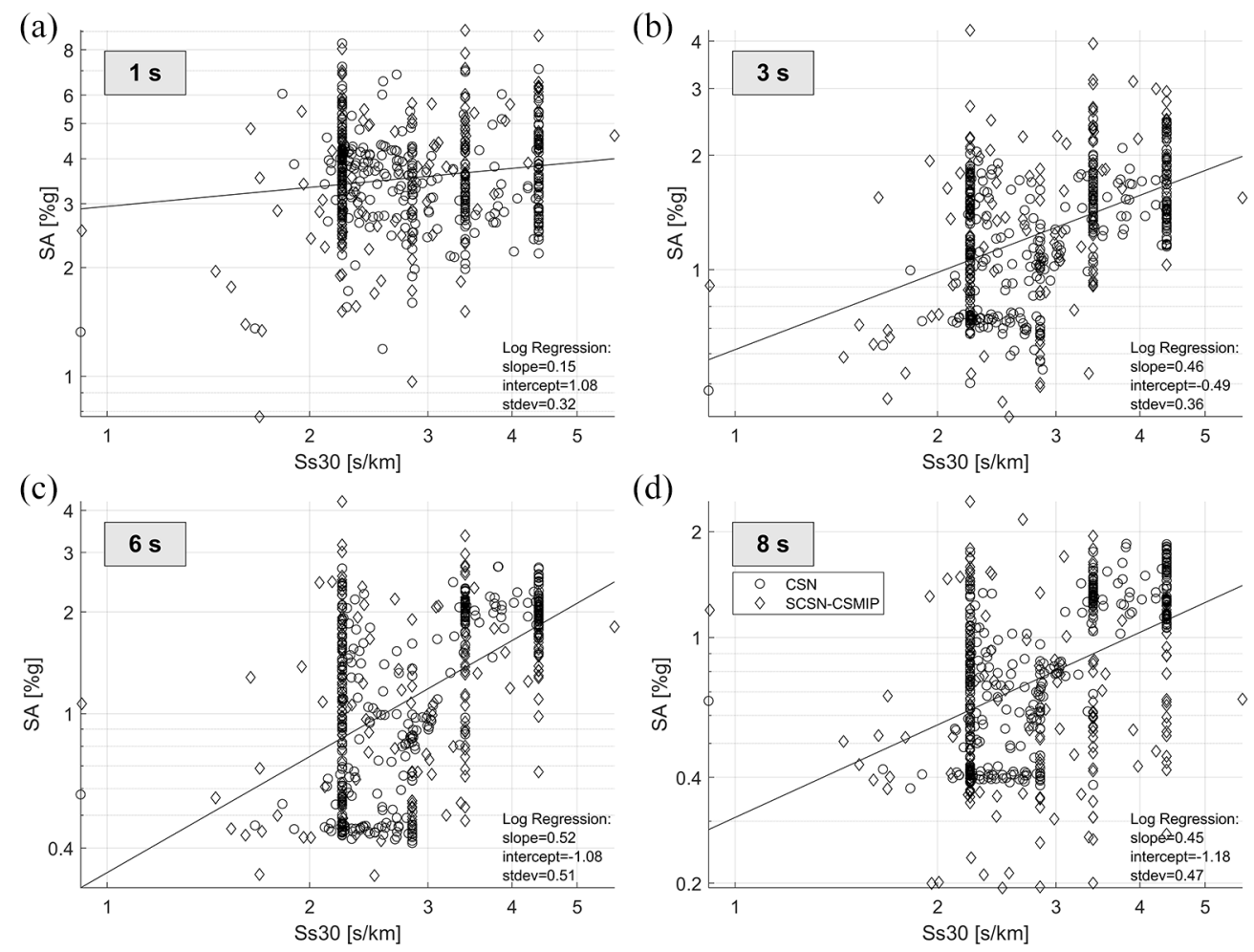

Figure 9. SA correlation with Ss 30 , for the M7.I earthquake-logarithmic scale. (a) $T=1 \mathrm{~s}$, (b) $T=3 \mathrm{~s}$, (c) $T=6 \mathrm{~s}$, and (d) $T=8 \mathrm{~s}$. Damping ratio $=5 \%$. Circles: CSN stations, Diamonds: SCSN and CSMIP stations. The solid line shows the least-squares (LS) regression fit performed in log-log scale. The slope and intercept of the LS regression line, and the standard deviation of the log values are provided in each subplot.

and depth-to-basement is found to be stronger than the correlation between SA and Ss30. Another possible reason, however, could be the hybrid approach used to derive the Vs30 values, where apart from site-specific Vs30 measurements, surface geological units and topographic gradient are also taken into account (Thompson et al., 2014). It is possible that these features contribute to the correlation observed for the longer periods.

\section{Ground motion simulation predictions}

Ground motion simulations for the M7.1 Ridgecrest event were performed using the 3D finite-difference method of Graves (1996). A suitable stochastic finite-fault rupture model was developed (Graves and Pitarka, 2020) using the Graves-Pitarka kinematic rupture generator method (Graves and Pitarka, 2016). The rupture model was constrained by the near-fault ground motion. The simulations use a minimum shear-wave velocity $\left(V_{S}\right)$ of $500 \mathrm{~m} / \mathrm{s}$ and $100 \mathrm{~m}$ grid spacing, which yield reliable results up to $1 \mathrm{~Hz}$. We recognize that the basin has velocities lower than $500 \mathrm{~m} / \mathrm{s}$ in the shallow near surface; however, these layers are relatively thin and generally impact frequencies of $1 \mathrm{~Hz}$ and higher. Anelastic attenuation $Q$ is modeled using the relations $Q_{S}=50 V_{S}$ (for $V_{S}$ in $\mathrm{km} / \mathrm{s}$ ) and $Q_{P}=2 Q_{S}$. 


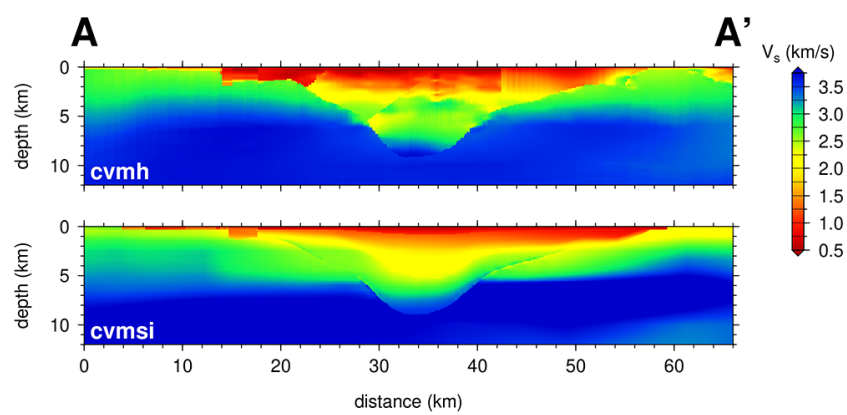

Figure 10. Shear-wave velocity cross sections for the two CVMs along profile A-A' (marked in Figure Ib).

The simulations were run in both CVM-S and CVM-H. The specific versions of the velocity models used are CVM-S4.26.M01 (Lee et al., 2014b) ("CVM-S" hereafter) and CVM-H15.10.0 (Shaw et al., 2015) ("CVM-H" hereafter). Due to differences in the approaches used to parameterize the models, the details of the Los Angeles Basin structure differ between the two models. In CVM-S, basin structure follows a rule-based seismic velocity model, derived mainly from well log data, where seismic velocity is a function of sediment age and depth. In CVM-H, basin velocities are determined from sonic logs and seismic reflection profiles collected by the petroleum industry. The models are further refined using waveform tomography with a variety of data sets including earthquakes, ambient noise, seismic reflection, and receiver functions. Both models utilize a highresolution geotechnical layer (GTL) based primarily on Vs30 values to represent the upper few hundred meters of the model; however, the implementation of the GTL is somewhat different in each model. Both CVMs are considered acceptable representations of the Southern California crustal structure, especially for periods longer than $5 \mathrm{~s}$ (Taborda et al., 2016).

Figure 10 displays the shear-wave velocity cross sections for the two models along the profile A-A' (marked in Figure 1b). Compared to CVM-S, CVM-H contains a sharper definition of the general basin structure. In addition, CVM-H contains several lateral discontinuities including several fault-bounded velocity jumps not present in CVM-S. CVM$\mathrm{H}$ has lower velocities in the upper 1-2 $\mathrm{km}$ of the basin compared to CVM-S, but higher velocities at $2-5 \mathrm{~km}$ depth. Below about $6 \mathrm{~km}$ depth, the velocities of the two models are similar.

Since the NGA-West2 GMPEs (Bozorgnia et al., 2014) offer RotD50 rather than SA predictions, we use the RotD50 intensity measure (Boore, 2010) for all comparisons between observations and model predictions. We calculate the model-predicted RotD50 from simulated waveforms low-pass filtered at $1 \mathrm{~Hz}$ using a fourth-order, two-pass Butterworth filter. Due to the bandwidth limitation, we only consider periods $T=3,6$, and $8 \mathrm{~s}$ for the SDoF oscillator. As before, we use a damping ratio of 5\%. Figure 11 displays maps of the model-predicted RotD50 for the two CVMs. The first column shows RotD50 maps calculated from the data (also available in Figure S4ACEG) for comparison. The different formulations of the two CVMs manifest themselves in the results. In the top few kilometers, the CVM-S model is overall smoother, while the CVM-H model contains sharp transitions and patches with large jumps in velocity (Figure 10). This is readily apparent in the results for $T=3 \mathrm{~s}$ where the RotD50 pattern for CVM-H is much more spatially complex than the pattern seen for CVM-S. The impact of these differences 


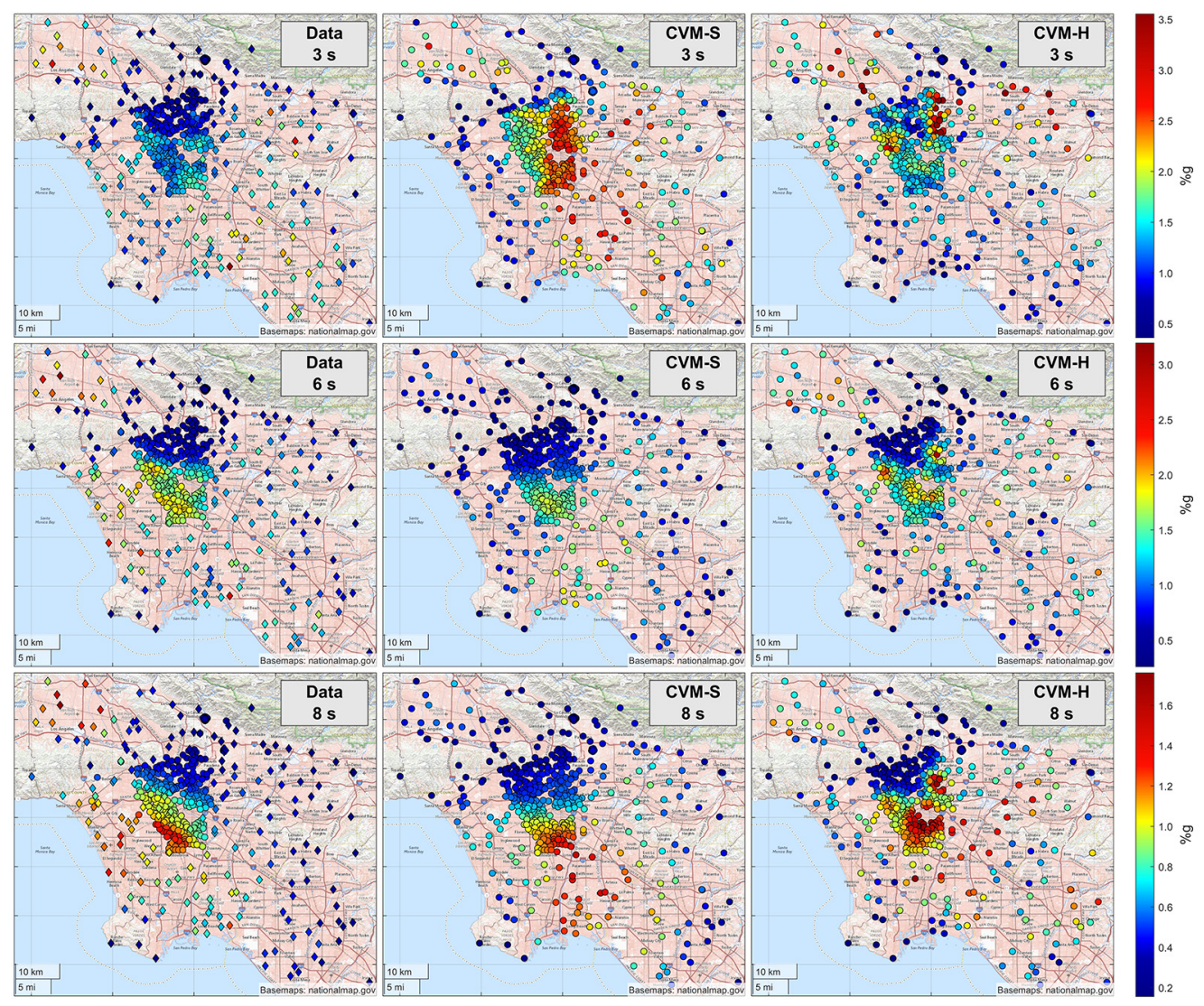

Figure I I. Data and model-predicted (simulations) RotD50 maps for the M7.I earthquake. Column I: Observations, Column 2: CVM-S model, Column 3: CVM-H model. Row I: $T=3 \mathrm{~s}$, Row 2: $T=6 \mathrm{~s}$, Row 3: $T=8 \mathrm{~s}$. Damping ratio $=5 \%$. Each row has a separate colorbar with different scales.

decreases moving to longer periods as the longer wavelengths become more sensitive to the larger-scale structure of the basin. At $8 \mathrm{~s}$ period, the patterns are fairly similar for the two models, although the peak amplitudes for CVM-H occur near the central basin (e.g. Downey), whereas they occur toward the southern margin of the basin (e.g. Long Beach) in CVM-S. We suspect that this difference results from the sharper vertical velocity gradient in CVM-H, which turns the waves more quickly toward the surface after they enter the basin from the northern margin.

In order to provide a more quantitative measure of the models' performance, we compute the residuals for geographical site $i, i=1, \ldots, N$ given by (Abrahamson et al., 1990):

$$
r_{i}(T, \zeta)=\ln \left(\frac{\operatorname{RotD50}_{\text {meas }, i}(T, \zeta)}{\operatorname{RotD50}_{\text {pred }, i}(T, \zeta)}\right)
$$

where $\operatorname{RotD} 50_{\text {meas }, i}(T, \zeta)$ is the RotD50 computed from the data and $\operatorname{RotD} 50_{\text {pred, } i}(T, \zeta)$ is the RotD50 predicted by the model, for site $i$. The model bias is given by: 


$$
B(T, \zeta)=\frac{1}{N} \sum_{i=1}^{N} r_{i}(T, \zeta)
$$

and the standard deviation is given by:

$$
\sigma(T, \zeta)=\left[\frac{1}{N} \sum_{i=1}^{N}\left[r_{i}(T, \zeta)-B(T, \zeta)\right]^{2}\right]^{1 / 2}
$$

We also compute the absolute misfit $(J)$ as a measure of the total mismatch between the simulation predictions and the data, found by:

$$
J(T, \zeta)=\frac{1}{N} \sum_{i=1}^{N}\left|r_{i}(T, \zeta)\right|
$$

The resulting model biases, standard deviations, and absolute misfits are given in Tables 1 to 3. Figure S15 in the supplement displays maps of the residuals. Positive residuals indicate that the model underpredicts the data, while negative residuals indicate

Table I. Model bias $B(T, \zeta=0.05)$ calculated using Equation 4 for the M7.I earthquake

\begin{tabular}{lcclc}
\hline & $T=1 \mathrm{~s}$ & $T=3 \mathrm{~s}$ & $T=6 \mathrm{~s}$ & $T=8 \mathrm{~s}$ \\
\hline CVM-S & - & -0.44 & 0.17 & 0.039 \\
CVM-H & - & -0.26 & 0.026 & -0.10 \\
ASKI4 & -0.14 & -0.016 & 0.62 & 0.40 \\
BSSAI4 & 0.16 & 0.10 & 0.65 & 0.55 \\
CBI4 & 0.14 & 0.25 & 0.95 & 0.81 \\
CYI4 & 0.048 & -0.082 & 1.12 & 1.25 \\
\hline
\end{tabular}

Table 2. Model standard deviation $\sigma(T, \zeta=0.05)$ calculated using Equation 5 for the M7.I earthquake

\begin{tabular}{lllll}
\hline & $T=I \mathrm{~s}$ & $T=3 \mathrm{~s}$ & $T=6 \mathrm{~s}$ & $T=8 \mathrm{~s}$ \\
\hline CVM-S & - & 0.36 & 0.30 & 0.38 \\
CVM-H & - & 0.47 & 0.37 & 0.47 \\
ASKI4 & 0.41 & 0.31 & 0.38 & 0.40 \\
BSSAI4 & 0.41 & 0.36 & 0.39 & 0.43 \\
CBI4 & 0.40 & 0.35 & 0.43 & 0.42 \\
CYI4 & 0.39 & 0.34 & 0.36 & 0.39 \\
\hline
\end{tabular}

Table 3. Model absolute misfit $J(T, \zeta=0.05)$ calculated using Equation 6 for the M7.I earthquake

\begin{tabular}{llllll}
\hline & $T=1 \mathrm{~s}$ & $T=3 \mathrm{~s}$ & $T=6 \mathrm{~s}$ & $T=8 \mathrm{~s}$ & Average \\
\hline CVM-S & - & 0.50 & 0.25 & 0.29 & 0.35 \\
CVM-H & - & 0.41 & 0.26 & 0.35 & 0.34 \\
ASKI4 & 0.36 & 0.25 & 0.63 & 0.47 & 0.43 \\
BSSAI4 & 0.36 & 0.30 & 0.69 & 0.62 & 0.49 \\
CBI4 & 0.35 & 0.34 & 0.95 & 0.82 & 0.61 \\
CYI4 & 0.32 & 0.28 & 1.12 & 1.25 & 0.74 \\
\hline
\end{tabular}


over-prediction. For both models, the total fit of the data is best (minimum $J$ ) at $T=6 \mathrm{~s}$ and worst (maximum $J$ ) at $T=3 \mathrm{~s}$. For the shorter period $(T=3 \mathrm{~s}), \mathrm{CVM}-\mathrm{H}$ has better performance (smaller $J$ ), while for the longer periods ( $T=6$ and $8 \mathrm{~s}$ ), the CVM-S performance is superior. Both models miss some areas where local maxima of RotD50 are observed (e.g. the San Fernando Valley and west Los Angeles for the longer periods).

The overall performance of the simulations is encouraging, with the average absolute misfit being about 0.35 for both models. For the longer periods ( $T=6$ and $8 \mathrm{~s}$ ), the range of the model-predicted SAs matches that of the observations. The drop in performance for $3 \mathrm{~s}$ is suspected to be due to the velocity structures not fitting well at these shorter periods. Developing the CVMs (e.g. waveform tomography information for the shorter periods, definition of the GTL, Vs30 values) and the various other components of the modeling (e.g. better inelastic attenuation factors, source modeling) are all potential paths for improvement.

\section{GMPE predictions}

We consider four out of the five GMPEs developed as part of the NGA-West2 project (Bozorgnia et al., 2014): ASK14 (Abrahamson et al., 2014), BSSA14 (Boore et al., 2014), CB14 (Campbell and Bozorgnia, 2014), and CY14 (Chiou and Youngs, 2014). The fifth GMPE (Idriss, 2014) is not applicable for our source-to-site distance or for the Vs30 ranges of our sites (Gregor et al., 2014), thus it is not considered. The equations explicitly consider the Vs30 of the site, as well as sediment thickness, which is parameterized as depth to shear-wave velocity of $1.0 \mathrm{~km} / \mathrm{s}(\mathrm{Z} 1.0)$ or $2.5 \mathrm{~km} / \mathrm{s}(\mathrm{Z} 2.5)$. In the following results, the Vs30 for each site was calculated using linear interpolation of the grid values from Thompson (2018), and the Z1.0 and Z2.5 were found using the CVM-H model. Using Z1.0 and Z2.5 from the CVM-S model yields similar GMPE predictions. Figure 12 shows the GMPE-based RotD50 estimate (median prediction) maps for periods $T=1,3,6$, and $8 \mathrm{~s}$ and damping ratio 5\%. Figure S16 in the supplement shows the associated residual (Equation 3) maps, and Tables 1 to 3 list the model biases, standard deviations, and absolute misfits, calculated using Equations 4 to 6.

The four GMPEs produce a wide range of spectral acceleration predictions. It is often the case that a GMPE performing well for one period does a poor job at a different period. For example, CY14 is the best performing GMPE (smallest $J$ ) at $T=1 \mathrm{~s}$ but performs poorly at $T=6$ and $8 \mathrm{~s}$. For the longer periods ( $T=6$ and $8 \mathrm{~s}$ ), all GMPEs suffer from underpredictions throughout the entire Los Angeles Basin. Weighting all four periods equally, ASK 14 has the best average performance. Like the simulations, the GMPEs miss locations where the observed RotD50 maxima occur (e.g. the San Fernando Valley and west Los Angeles, for the longer periods). When compared with the performance of the simulations, the GMPEs perform better (smaller $J$ ) for the 3-s period, while for the longer periods ( $T=6$ and $8 \mathrm{~s}$ ) the simulations have better performance.

It is worth mentioning that the presented GMPE predictions have large standard deviations. The GMPEs considered here are average models that may not always work well for a specific site and earthquake. When using these models, there is often the assumption that the site-specific differences and geologic variations will be captured by the large variability in the predictions. GMPE predictions at the basin sites might improve as additional observations become available. However, the observed poor correlation between the groundmotion response and site parameters (e.g. Figures 8 and 9), especially for the shorter periods, suggest that the added ground motion data may not always offer improvement. 


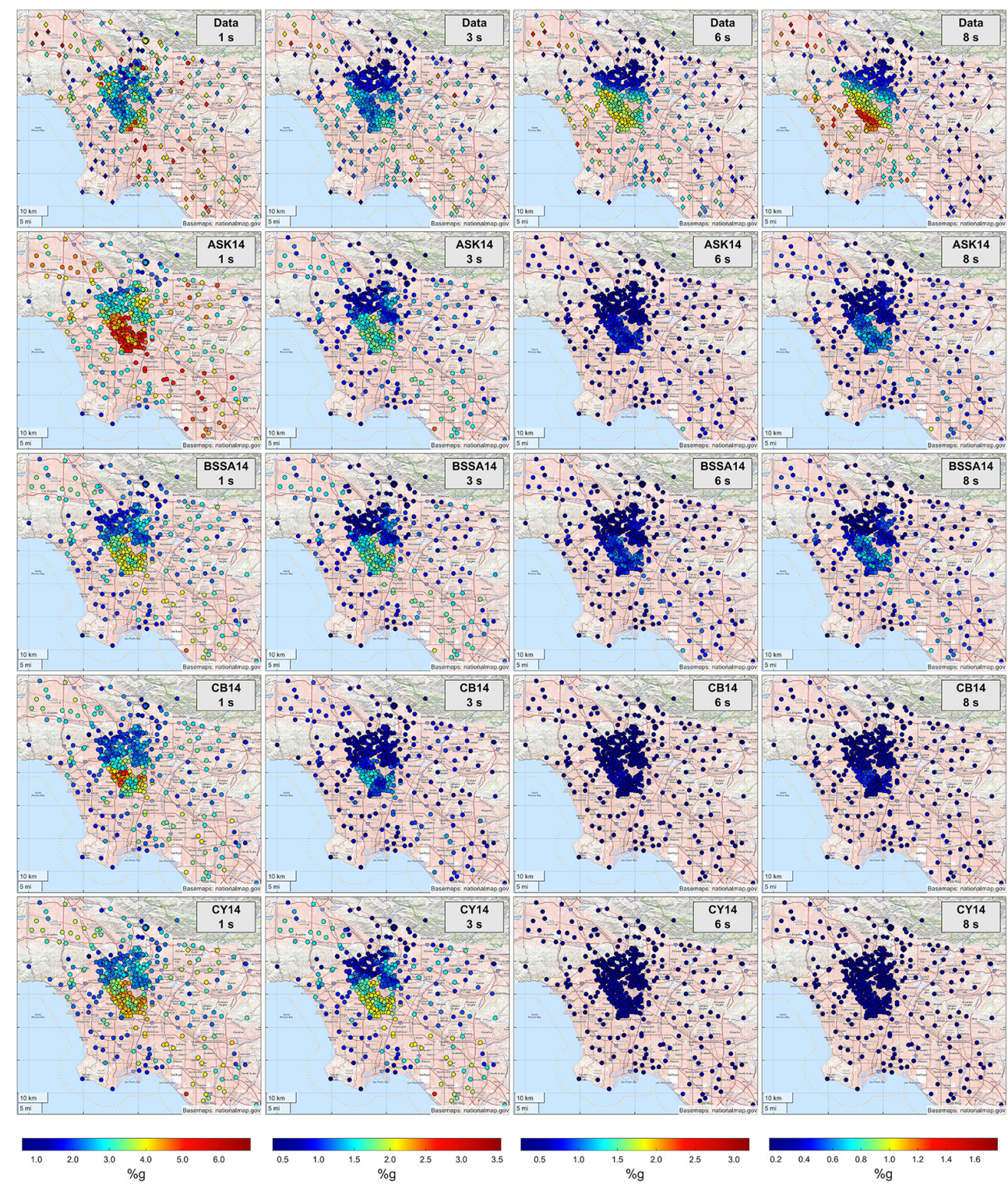

Figure 12. Data and model-predicted (GMPEs) RotD50 maps for the M7.I earthquake. Column I: $T=1 \mathrm{~s}$, Column 2: $T=3 \mathrm{~s}$, Column 3: $T=6 \mathrm{~s}$, Column 4: $T=8 \mathrm{~s}$. Row I: Observations, Row 2: ASK 14, Row 3: BSSA 14, Row 4: CBI4, Row 5: CYI4. Damping ratio $=5 \%$. Each column has a separate colorbar with different scales.

Reconsidering the input site parameters and including new site parameters in the GMPEs may allow for further improvement, but at the expense of added complexity in GMPE implementation. Another alternative for improved performance is the use of non-ergodic ground motion models (e.g. Kuehn et al., 2019; Landwehr et al., 2016) and non-ergodic site response models (e.g. Stewart et al., 2017) that are specific to the Los Angeles basin region. 


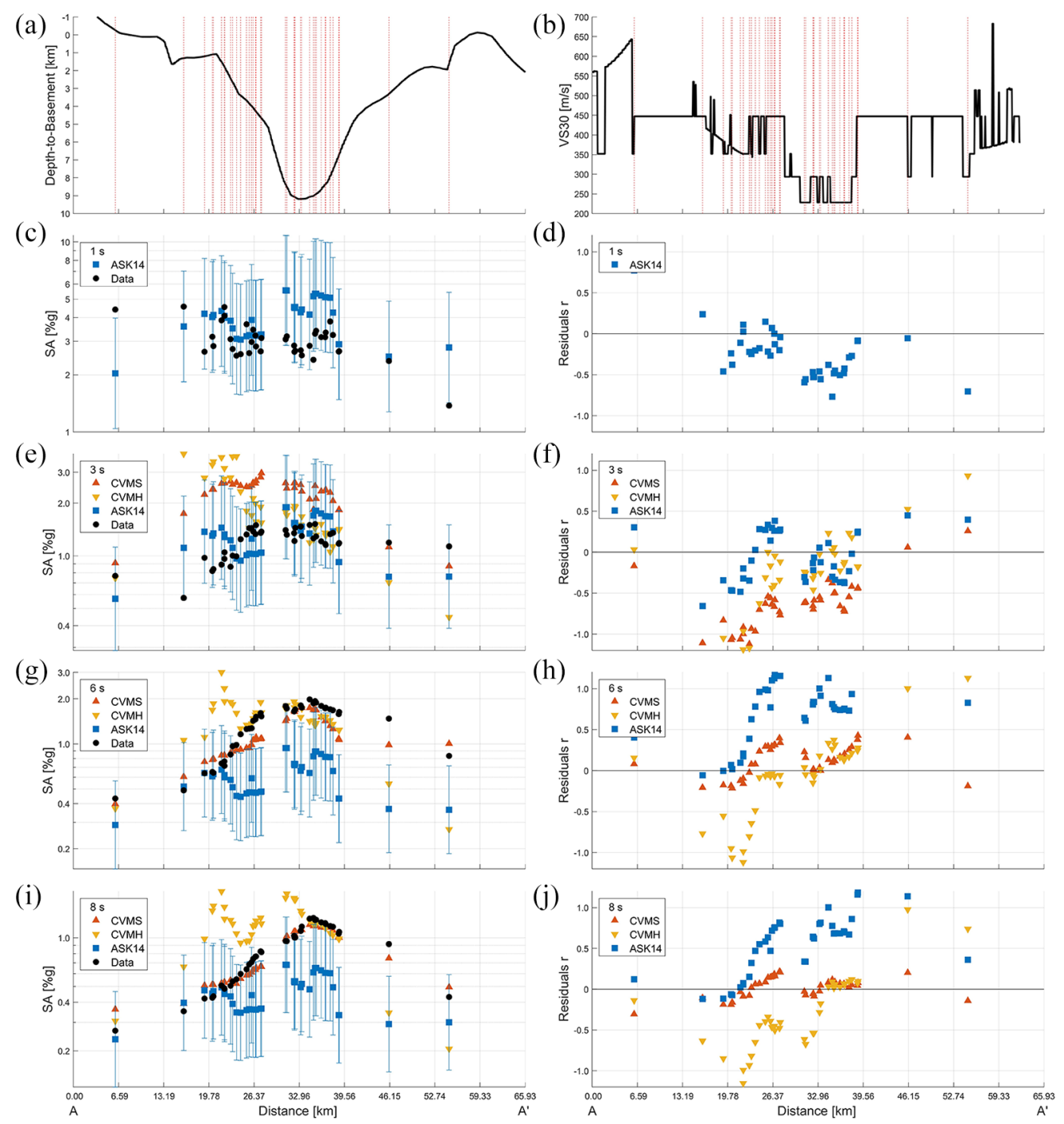

Figure 13. Performance along the profile A-A' for the M7.I earthquake. (a) Depth-to-basement along the profile. (b) Vs30 along the profile. (c to j) Left column: RotD50 values, Right column: Residuals (Equation 3). (c and d) $T=1 \mathrm{~s}$. (e and $\mathrm{f}$ ) $T=3 \mathrm{~s}$. (g and h) $T=6 \mathrm{~s}$. (i and j) $T=8 \mathrm{~s}$. Damping ratio $=5 \%$. Black circles: data, Red Triangles: CVM-S model simulations, Orange triangles (downward-pointing): CVM-H model simulations, Blue squares: ASK I4 GMPE predictions. For the GMPE predictions, the squares mark the median values and the error bars mark the \pm I standard deviation.

\section{Model predicted spectral acceleration across profile A-A'}

In the previous sections, we considered maps of the model-predicted RotD50 (Figures 11 and 12) and the residuals throughout the Los Angeles Basin (Figures S15 and S16). These maps offer a good overview of the model performance and allow easy comparison of specific areas or stations. A different way of presenting the above results is by considering profile A-A' across the Los Angeles Basin. Figure 13 displays the observed and predicted RotD50 values calculated for the 40 closest stations to this profile. We use only one 
GMPE here-ASK14, since it had the smallest average absolute misfit $(J)$ for the four considered periods. Figure 13a and $\mathrm{b}$ present the depth-to-basement and Vs30 profiles along A-A'. The left column shows RotD50 values for periods $T=1,3,6$, and 8 s, and damping ratio $5 \%$, and the right column shows the residuals (calculated from Equation 3 ). For the GMPE predictions, the points mark the median predicted RotD50, and the error bars mark \pm 1 standard deviation.

Along our selected profile, the GMPE (ASK14) shows a reasonably good performance for the two shorter periods ( $T=1$ and $3 \mathrm{~s}$ ); however, it mostly underpredicts the RotD50 in the deeper parts of the basin for the longer periods $(T=6$ and $8 \mathrm{~s})$. For $T=3 \mathrm{~s}$, the simulations overpredict the basin RotD50 at many stations and their performance is equivalent or worse than the GMPEs. However, for $T=6 \mathrm{~s}$, the performance of both simulations is superior. For the longest period, $T=8 \mathrm{~s}$, the CVM-H simulations suffer from overpredictions, while CVM-S fits the data exceptionally well. Looking at the \pm 1 standard deviation error bars, one sees the large standard deviations that come with the GMPE predictions. For our data set, it is often the case that the GMPE prediction is poor but the observed values fall within the \pm 1 standard deviation.

\section{Discussion}

The SA maps produced from the Ridgecrest data (Figures 2 and 3) can be used as a simplified measure of the infrastructure response and are structure-type specific by accounting for different fundamental periods. For structures with long periods, amplification of these long-period motions can be hazardous. In urban Los Angeles, the vulnerable long-period structures include high-rise buildings, large-diameter liquid storage tanks, and long-span bridges. The high-rises are mainly located in downtown Los Angeles. In the Ridgecrest events, the downtown area experienced SAs for $T=6$ and $8 \mathrm{~s}$ (Figures $2 \mathrm{e}$ to h and S7E to $\mathrm{H}$ ) that were at least a factor of 2 higher (with some downtown sites observed to have up to a factor of 5 higher, for $T=6 \mathrm{~s}$ ) than that of hard-rock sites to the north of the basin (e.g. in San Rafael Hills and Mt. Wilson) (see also Kohler et al., 2020). Large-diameter liquid storage tanks are known to have long fundamental periods due to fluid sloshing and are thus sensitive to these longer periods. For instance, a circular tank with a radius of $25 \mathrm{~m}$ and height of $20 \mathrm{~m}$ has a sloshing period of approximately $8 \mathrm{~s}$ (Housner, 1954). Liquid storage tanks are very common in the Los Angeles Basin, especially in the southern part (near the Port of Los Angeles and oil refineries). During the Ridgecrest earthquakes, this area experienced large SA amplifications at $T=8 \mathrm{~s}$ relative to the hard-rock sites to the north of the basin (Figures $2 \mathrm{~g}$ and $\mathrm{h}$ and $\mathrm{S} 7 \mathrm{G}$ and $\mathrm{H}$ ). In the case of a larger future event, such amplifications could be critical, possibly even causing severe damage and/or fire in oil storage tanks, similar to what occurred in the city of Tomakomai during the 2003 Tokachi-oki earthquake (Hatayama, 2008).

Several previous studies have also used earthquake records to create amplification maps for the Los Angeles region. Hartzell et al. (1998) analyzed records from the 1971 San Fernando, 1987 Whittier Narrows, 1991 Sierra Madre, and 1994 Northridge earthquakes and reported Fourier spectra amplification factors relative to a hard-rock site in the Santa Monica Mountains for frequencies down to $1 \mathrm{~Hz}$. Their lowest frequency band of $1-3 \mathrm{~Hz}$ (which is roughly comparable with our 1-s maps) shows amplification factors of 3-4 over the deepest portion of the central Los Angeles basin. These results are generally consistent with what we find for the Ridgecrest events. 
More recently, Hatayama and Kalkan (2011) utilized recordings for the 2010 El MayorCucapah earthquake to produce long-period (4-s and longer) Fourier spectra amplification maps throughout the Los Angeles region. For their longest periods ( 8 and $10 \mathrm{~s}$ ), they found a broad zone of strong amplification over the central Los Angeles basin with a maximum amplification of 5 relative to their reference hard-rock stations. At periods of 4 and $6 \mathrm{~s}$, the amplification patterns become more complex with several local maxima within the basin. The largest amplification factor they found was 10 at 6-s period in a region located along the western margin of the Los Angeles basin (e.g. near Manhattan Beach). They also compared the amplification patterns with depth to various isovelocity surfaces within CVM-H and found good correlation of increased amplification with large isovelocity surface depth for periods of 8 and $10 \mathrm{~s}$, but much lower correlation at the shorter periods. Due to inherent differences in Fourier spectra and response spectral acceleration, it is difficult to directly compare our results to these. Nonetheless, the general trends and observations are consistent with our findings, including the strong 6-s amplification found along the western margin of the LA basin, which shows little correlation with depth-to-basement in the current CVMs.

As data from new events become available and with the station density and numbers ever increasing, the resulting intensity measure maps will continue to evolve in accuracy and spatial resolution. It is important that maps constructed from observations are considered for pre-earthquake structure design and infrastructure planning, since there is not always a clear correlation between the measured intensities and the commonly used site parameters.

In recent years, there is a growing effort for site-specific seismic hazard analysis, with documents such the Alternative Analysis \& Design Procedure guidelines published by the Los Angeles Tall Building Seismic Design Council (LATBSDC, 2008), and projects such as SCEC's Committee for Utilization of Ground Motions Simulations (UGMS) (e.g. Crouse et al., 2018). We hope that this work will bring attention to the potential shortcomings of the currently used site parameters (Z1.0, Z2.5, and Vs30) and CVMs. The refinement of these parameters and models in light of new dense data is essential and will benefit greatly existing guidelines and projects.

\section{Conclusion}

We constructed assessments of the geographical variability of ground motions in the Los Angeles region during the two largest events of the 2019 Ridgecrest earthquake sequence. These are presented in the form of spectral acceleration maps for four periods of engineering significance $(T=1,3,6$, and $8 \mathrm{~s})$. For the longer periods, coherent SA patterns are present throughout the Los Angeles Basin, while for shorter periods, the dense CSN instrumentation allows us to see the increased spatial complexity and the smaller length scale pockets of SA amplification. Basement depths and Vs30 are parameters commonly used to predict the ground response. Examining the correlation of the observed ground motions with depth-to-basement, Z1.0, Z2.5, and Ss30, we find the correlation to be stronger for the longer periods. The lack of strong correlation at shorter periods suggests that other factors are influencing the response beyond what is captured considering the above parameters alone. The poor correlation of the Vs30 parameter is likely related to the precision of the proxy-based Vs30 estimates. The correlation with depth-related parameters might also appear degraded due to the fact that the true values of these parameters are not known. An effort should be made toward realizing any additional factors influencing 
the ground response. Possible factors could be the complex geologic structure within the basin, which includes lateral contrasts due to folding and faulting, as well as the variability in shallow geologic deposits connected with current and ancient watershed systems.

Using the data collected from the M7.1 main shock, we examined the performance of 3D ground-motion simulations using two different velocity models (CVM-S and CVM-H), as well as the performance of four NGA-West2 GMPEs. For specific cases, the agreement between the observations and the model predictions is good but there is room for improvement. Comparing the two velocity models, we find that CVM-S is superior for the longer periods $(T=6$ and $8 \mathrm{~s})$, while CVM-H performs better for $T=3 \mathrm{~s}$. The differences in the ground-motion simulations can be associated with the different representations of the two velocity models for the Los Angeles Basin. The GMPEs suffer from underpredictions for the longer periods, but generally perform better at the shorter periods. However, it is often the case that a GMPE performing well for one period does a poor job at a different period. Comparing the simulations with the GMPEs, one potential benefit of the simulations is that they produce full waveforms that can also be used for further studies and dynamic analyses (e.g. Krishnan et al., 2006). For $T=3 \mathrm{~s}$, the GMPEs perform better, while for the longer periods ( $T=6$ and $8 \mathrm{~s}$ ), the simulations perform better than the GMPEs. While both simulations and GMPE estimates often reproduce the general amplitudes and trends of the groundmotion response, they have trouble capturing the finer-scale spatial variations of the observed response, as well as matching the specific locations of the maximum amplifications. This stresses the need for caution and further validation when employing these methods.

\section{Data and resources}

The data from the Community Seismic Network (CSN) stations for the two Ridgecrest events is publicly available through the CSN website at http://csn.caltech.edu/data/. The Southern California Seismic Network (SCSN) data was accessed through the Southern California Earthquake Data Center (SCEDC) and are available at https://scedc.caltech.edu/. The California Strong Motion Instrumentation Program (CSMIP) data was accessed through the Center for Engineering Strong Motion Data (CESMD) and are available at https://strongmotioncenter.org/. All data used in this study from the three above sources is also archived on the SCEDC and can be accessed at https://scedc.caltech.edu/research-tools/ridgecrest-info.html/. The topographic background base maps were made available by the U.S. Geological Survey's (USGS) National Geospatial Program and were accessed from https://basemap.nationalmap.gov/. The regional basement surface and major faults data are provided by Southern California Earthquake Center's (SCEC) Unified Structural Representation (USR) and are available at SCEC's GitHub repository https://github.com/SCECcode/. The Vs30 data are released by USGS and were accessed through https://www.sciencebase.gov/catalog/. The 3D seismic velocity models were accessed using the SCEC UCVM software, version 19.4.0 (https://github.com/SCECcode/ UCVMC/wiki/). All above electronic addresses were last accessed on April 2020.

\section{Acknowledgments}

We acknowledge the Texas Advanced Computing Center (TACC) at The University of Texas at Austin (http://www.tacc.utexas.edu/) for providing high-performance computing resources through an allocation to the Southern California Earthquake Center (SCEC). We thank John H. Shaw and Andreas Plesch for providing assistance in obtaining the regional basement topography data. The authors appreciate the constructive reviews of the manuscript provided by Morgan Page and Grace Parker. 


\section{Declaration of conflicting interests}

The author(s) declared no potential conflicts of interest with respect to the research, authorship, and/ or publication of this article.

\section{Funding}

The author(s) disclosed receipt of the following financial support for the research, authorship, and/ or publication of this article: We are grateful to Caltech, the Betty and Gordon Moore Foundation, the Conrad N. Hilton Foundation, and Computers \& Structures, Inc., for funding this project and for supporting the continuous operation of the Community Seismic Network. This research was also supported by the Southern California Earthquake Center (Contribution No. 10931). SCEC is funded by NSF Cooperative Agreement EAR-1600087 \& USGS Cooperative Agreement G17AC00047. The first author was supported by the Cecil and Sally Drinkward Graduate Fellowship at the California Institute of Technology.

\section{ORCID iDs}

Filippos Filippitzis (DD https://orcid.org/0000-0001-8377-4914

K Mani Chandy (iD https://orcid.org/0000-0001-9190-1290

\section{Supplemental material}

Supplemental material for this article is available online.

\section{References}

Abrahamson NA, Silva WJ and Kamai R (2014) Summary of the ASK14 ground motion relation for active crustal regions. Earthquake Spectra 30(3): 1025-1055.

Abrahamson NA, Somerville PG and Cornell AC (1990) Uncertainty in numerical strong motion predictions. Proceedings of the Fourth U.S. National Conference on Earthquake Engineering 1: 407-416.

Ahdi SK, Mazzoni S, Kishida T, Wang P, Nweke CC, Kuehn NM, Contreras V, Rowshandel B, Stewart JP and Bozorgnia Y (2020) Engineering characteristics of ground motions recorded in the 2019 Ridgecrest earthquake sequence. Bulletin of the Seismological Society of America 110(4): 1474-1494.

Ancheta TD, Darragh RB, Stewart JP, Seyhan E, Silva WJ, Chiou BSJ, Wooddell KE, Graves RW, Kottke AR, Boore DM, Kishida T and Donahue JL (2014) NGA-West2 database. Earthquake Spectra 30(3): 989-1005.

Andrews J (2019) 07/2019, Ridgecrest sequence: M6.4 and M7.1. SCSN. Available at: https:// www.scsn.org/index.php/2019/07/04/07-2019-ridgecrest-sequence/index.html (accessed 17 April 2020).

Baltzopoulos G, Luzi L and Iervolino I (2020) Analysis of near-source ground motion from the 2019 Ridgecrest earthquake sequence. Bulletin of the Seismological Society of America 110(4): $1495-1505$.

Boore DM (2010) Orientation-independent, nongeometric-mean measures of seismic intensity from two horizontal components of motion. Bulletin of the Seismological Society of America 100(4): $1830-1835$.

Boore DM, Stewart JP, Seyhan E and Atkinson GM (2014) NGA-West2 equations for predicting PGA, PGV, and 5\% damped PSA for shallow crustal earthquakes. Earthquake Spectra 30(3): 1057-1085.

Bozorgnia Y, Abrahamson NA, Atik LA, Ancheta TD, Atkinson GM, Baker JW, Baltay A, Boore DM, Campbell KW, Chiou BSJ, Darragh R, Day S, Donahue J, Graves RW, Gregor N, Hanks T, Idriss IM, Kamai R, Kishida T, Kottke A, Mahin SA, Rezaeian S, Rowshandel B, Seyhan E, 
Shahi S, Shantz T, Silva W, Spudich P, Stewart JP, Watson-Lamprey J, Wooddell K and Youngs R (2014) NGA-West2 research project. Earthquake Spectra 30(3): 973-987.

Brown LT, Boore DM and Stokoe KH (2002) Comparison of shear-wave slowness profiles at 10 strong-motion sites from noninvasive SASW measurements and measurements made in boreholes. Bulletin of the Seismological Society of America 92(8): 3116-3133.

California Institute of Technology and United States Geological Survey Pasadena (Caltech and USGS) (1926). Southern California Seismic Network. International Federation of Digital Seismograph Networks. DOI: 10.7914/SN/CI.

Campbell KW (1976) A note on the distribution of earthquake damage in Long Beach, 1933. Bulletin of the Seismological Society of America 66(3): 1001-1005.

Campbell KW and Bozorgnia Y (2014) NGA-West2 ground motion model for the average horizontal components of PGA, PGV, and 5\% damped linear acceleration response spectra. Earthquake Spectra 30(3): 1087-1115.

Chiou BJ and Youngs RR (2014) Update of the Chiou and Youngs NGA model for the average horizontal component of peak ground motion and response spectra. Earthquake Spectra 30(3): $1117-1153$.

Chopra AK (2011) Dynamics of Structures: Theory and Applications to Earthquake Engineering. 4th ed. Upper Saddle River, NJ: Pearson Prentice Hall.

Clayton RW, Heaton T, Kohler M, Chandy M, Guy R and Bunn J (2015) Community seismic network: A dense array to sense earthquake strong motion. Seismological Research Letters 86(5): 1354-1363.

Clayton RW, Kohler M, Guy R, Bunn J, Heaton T and Chandy M (2020) CSN-LAUSD network: A dense accelerometer network in Los Angeles schools. Seismological Research Letters 91: 622-630.

Crouse CB, Jordan TH, Milner KR, Goulet CA, Callaghan S and Graves RW (2018) Site-specific MCER response spectra for Los Angeles region based on 3-D numerical simulations and the NGA West2 equations. In: Proceedings of the 11th national conference in earthquake engineering, 25-29 June, Paper \#518. Los Angeles, CA: Earthquake Engineering Research Institute.

Cruz C and Miranda E (2017) Evaluation of damping ratios for the seismic analysis of tall buildings. Journal of Structural Engineering 143(1): 0416144.

Gao S, Liu H, Davis PM and Knopoff L (1996) Localized amplification of seismic waves and correlation with damage due to the Northridge earthquake: Evidence for focusing in Santa Monica. Bulletin of the Seismological Society of America 86(1B): S209-S230.

Graves RW (1996) Simulating seismic wave propagation in 3D elastic media using staggered-grid finite differences. Bulletin of the Seismological Society of America 86(4): 1091-1106.

Graves RW and Pitarka A (2016) Kinematic ground-motion simulations on rough faults including effects of 3D stochastic velocity perturbations. Bulletin of the Seismological Society of America 106(5): 2136-2153.

Graves RW and Pitarka A (2020) 3D ground motion simulations for events in the 2019 Ridgecrest sequence. In: 17th world conference on earthquake engineering (17WCEE), Sendai, Japan, 13-18 September.

Graves RW, Pitarka A and Somerville PG (1998) Ground-motion amplification in the Santa Monica area: Effects of shallow basin-edge structure. Bulletin of the Seismological Society of America 88(5): 1224-1242.

Gregor N, Abrahamson NA, Atkinson GM, Boore DM, Bozorgnia Y, Campbell KW, Chiou BSJ, Idriss IM, Kamai R, Seyhan E, Silva W, Stewart JP and Youngs R (2014) Comparison of NGAWest2 GMPEs. Earthquake Spectra 30(3): 1179-1197.

Harmsen SC (1997) Determination of site amplification in the Los Angeles urban area from inversion of strong-motion records. Bulletin of the Seismological Society of America 87(4): 866-887.

Hartzell S, Harmsen S, Frankel A, Carver D, Cranswick E, Meremonte M and Michael J (1998) First-generation site-response maps for the Los Angeles region based on earthquake ground motions. Bulletin of the Seismological Society of America 88(2): 463-472. 
Hartzell S, Leeds A, Frankel A and Michael J (1996) Site response for urban Los Angeles using aftershocks of the Northridge earthquake. Bulletin of the Seismological Society of America 86(1B): S168-S192.

Hatayama K (2008) Lessons from the 2003 Tokachi-oki, Japan, earthquake for prediction of longperiod strong ground motions and sloshing damage to oil storage tanks. Journal of Seismology 12(2): 255-263.

Hatayama K and Kalkan E (2011) Long-period (3 to 10 s) ground motions in and around the Los Angeles basin during the Mw 7.2 El-Mayor Cucapah Earthquake of April 4, 2010. In: Proceedings of the 4th IASPEI/IAEE international symposium, Santa Barbara, CA, 23-26 August, pp. 23-26. Santa Barbara, CA: University of California.

Hauksson E, Yoon C, Yu E, Andrews J, Alvarez M, Bhadha R and Thomas V (2020) Caltech/USGS Southern California Seismic Network (SCSN) and Southern California Earthquake Data Center (SCEDC): Data Availability for the 2019 Ridgecrest Sequence. Seismological Research Letters 91: 1961-1970.

Hays WW (1984) Technical problems in the construction of a map to zone the earthquake groundshaking hazard in the United States. Engineering Geology 20(1-2): 13-23.

Housner GW (1941) Calculating the response of an oscillator to arbitrary ground motion. Bulletin of the Seismological Society of America 31(2): 143-149.

Housner GW (1954) Earthquake Pressures on Fluid Containers. Pasadena, CA: California Institute of Technology.

Idriss IM (2014) An NGA-West2 empirical model for estimating the horizontal spectral values generated by shallow crustal earthquakes. Earthquake Spectra 30(3): 1155-1177.

Kohler MD, Filippitzis F, Heaton T, Clayton RW, Guy R, Bunn J and Chandy KM (2020) 2019 Ridgecrest earthquake reveals areas of Los Angeles that amplify shaking of high-rises. Seismological Research Letters 91: 3370-3380.

Kohler MD, Magistrale H and Clayton RW (2003) Mantle heterogeneities and the SCEC reference three-dimensional seismic velocity model version 3. Bulletin of the Seismological Society of America 93(2): 757-774.

Komatitsch D, Liu Q, Tromp J, Suss P and Stidham C (2004) Simulations of ground motion in the Los Angeles basin based upon the spectral-element method. Bulletin of the Seismological Society of America 94(1): 187-206.

Krishnan S, Ji C, Komatitsch D and Tromp J (2006) Case studies of damage to tall steel momentframe buildings in southern California during large San Andreas earthquakes. Bulletin of the Seismological Society of America 96(4A): 1523-1537.

Kuehn NM, Abrahamson NA and Walling MA (2019) Incorporating nonergodic path effects into the NGA-West2 ground-motion prediction equations. Bulletin of the Seismological Society of America 109(2): 575-585.

Landwehr N, Kuehn NM, Scheffer T and Abrahamson N (2016) A nonergodic ground-motion model for California with spatially varying coefficients. Bulletin of the Seismological Society of America 106(6): 2574-2583.

Lee CF, Lee JC and Lee AC (2000) Statistics for Business and Financial Economics. 3rd ed. Singapore: Singapore World Scientific.

Lee EJ, Chen P and Jordan TH (2014a) Testing waveform predictions of 3D velocity models against two recent Los Angeles earthquakes. Seismological Research Letters 85(6): 1275-1284.

Lee EJ, Chen P, Jordan TH, Maechling PB, Denolle MAM and Beroza GC (2014b) Full-3-D tomography for crustal structure in southern California based on the scattering-integral and the adjoint-wavefield methods. Journal of Geophysical Research: Solid Earth 119(8): 6421-6451.

Lin RG II (2019) Earthquake shook L.A. skyscrapers so hard some got vertigo. Los Angeles Times, 15 August. Available at: https://www.latimes.com/california/story/2019-08-14/ridgecrestearthquake-produced-minutes-of-shaking-new-story (accessed 17 April 2020).

Liu HL and Heaton TH (1984) Array analysis of the ground velocities and accelerations from the 1971 San Fernando, California, earthquake. Bulletin of the Seismological Society of America 74(5): 1951-1968. 
Los Angeles Tall Buildings Structural Design Council (LATBSDC) (2008) An Alternative Procedure for Seismic Analysis and Design of Tall Buildings Located in the Los Angeles Region. Los Angeles, CA: LATBSDC.

Magistrale H, Day S, Clayton RW and Graves RW (2000) The SCEC southern California reference three-dimensional seismic velocity model version 2. Bulletin of the Seismological Society of America 90(6B): S65-S76.

Olsen KB, Archuleta RJ and Matarese JR (1995) Three-dimensional simulation of a magnitude 7.75 earthquake on the San Andreas fault. Science 270(5242): 1628-1632.

Olsen KB, Day SM and Bradley CR (2003) Estimation of Q for long-period ( $>2 \mathrm{sec}$ ) waves in the Los Angeles basin. Bulletin of the Seismological Society of America 93(2): 627-638.

Petersen MD, Frankel AD, Harmsen SC, Mueller CS, Haller KM, Wheeler RL, Wesson RL, Zeng Y, Boyd OS, Perkins DM, Luco N, Field EH, Wills CJ and Rukstales KS (2008) Documentation for the 2008 Update of the United States National Seismic Hazard Maps (No. 2008-1128). Reston, VA: U.S. Geological Survey.

Rodgers AJ, Pitarka A, Petersson NA, Sjögreen B and McCallen DB (2018) Broadband $(0-4 \mathrm{~Hz})$ ground motions for a magnitude 7.0 Hayward fault earthquake with three-dimensional structure and topography. Geophysical Research Letters 45(2): 739-747.

Rogers AM, Borcherdt RD, Covington PA and Perkins DM (1984) A comparative ground response study near Los Angeles using recordings of Nevada nuclear tests and the 1971 San Fernando earthquake. Bulletin of the Seismological Society of America 74(5): 1925-1949.

Rogers AM, Tinsley JC, Hays WW and King KW (1979) Evaluation of the relation between nearsurface geological units and ground response in the vicinity of Long Beach, California. Bulletin of the Seismological Society of America 69(5): 1603-1622.

Roten D, Olsen KB, Day SM and Cui Y (2017) Quantification of fault-zone plasticity effects with spontaneous rupture simulations. Pure and Applied Geophysics 174(9): 3369-3391.

Saikia CK, Dreger DS and Helmberger DV (1994) Modeling of energy amplification recorded within greater Los Angeles using irregular structure. Bulletin of the Seismological Society of America 84(1): 47-61.

Shaw JH, Plesch A, Tape C, Suess MP, Jordan TH, Ely G, Hauksson E, Tromp J, Tanimoto T, Graves R, Olsen K, Nicholson C, Maechling PJ, Rivero C, Lovely P, Brankman CM and Munster J (2015) Unified structural representation of the southern California crust and upper mantle. Earth and Planetary Science Letters 415: 1-15.

Shi Z and Day SM (2013) Rupture dynamics and ground motion from 3-D rough-fault simulations. Journal of Geophysical Research: Solid Earth 118(3): 1122-1141.

Stewart JP, Afshari K and Goulet CA (2017) Non-ergodic site response in seismic hazard analysis. Earthquake Spectra 33(4): 1385-1414.

Süss MP and Shaw JH (2003) P wave seismic velocity structure derived from sonic logs and industry reflection data in the Los Angeles basin, California. Journal of Geophysical Research: Solid Earth 108(B3): 2170-2181.

Taborda R and Bielak J (2013) Ground-motion simulation and validation of the 2008 Chino Hills, California, earthquake. Bulletin of the Seismological Society of America 103(1): 131-156.

Taborda R and Bielak J (2014) Ground-motion simulation and validation of the 2008 Chino Hills, California, earthquake using different velocity models. Bulletin of the Seismological Society of America 104(4): 1876-1898.

Taborda R, Azizzadeh-Roodpish S, Khoshnevis N and Cheng K (2016) Evaluation of the southern California seismic velocity models through simulation of recorded events. Geophysical Journal International 205(3): 1342-1364.

Thompson EM (2018) An Updated Vs30 Map for California with Geologic and Topographic Constraints. Reston, VA: U.S. Geological Survey.

Thompson EM, Wald DJ and Worden CB (2014) A VS30 map for California with geologic and topographic constraints. Bulletin of the Seismological Society of America 104(5): 2313-2321.

Vidale JE and Helmberger DV (1988) Elastic finite-difference modeling of the 1971 San Fernando, California earthquake. Bulletin of the Seismological Society of America 78(1): 122-141. 
Wald DJ and Graves RW (1998) The seismic response of the Los Angeles basin, California. Bulletin of the Seismological Society of America 88(2): 337-356.

Withers KB, Olsen KB and Day SM (2015) Memory-efficient simulation of frequency-dependent Q. Bulletin of the Seismological Society of America 105(6): 3129-3142.

Withers KB, Olsen KB, Day SM and Shi Z (2019) Ground motion and intraevent variability from 3D deterministic broadband $(0-7.5 \mathrm{~Hz})$ simulations along a nonplanar strike-slip fault. Bulletin of the Seismological Society of America 109(1): 229-250.

Wollherr S, Gabriel AA and Uphoff C (2018) Off-fault plasticity in three-dimensional dynamic rupture simulations using a modal Discontinuous Galerkin method on unstructured meshes: Implementation, verification and application. Geophysical Journal International 214(3): $1556-1584$.

\section{Appendix I}

The RotD50 and RotD100 intensity measures as defined by Boore (2010) are computed as follows. Since the system is linear, the oscillator displacements in the two horizontal directions $\left(u_{x}(t)\right.$ and $\left.u_{y}(t)\right)$ are combined into a single time series corresponding to a rotation angle $\theta$ using the equation:

$$
u_{c m b}(t, \theta)=u_{x}(t) \cos \theta+u_{y}(t) \sin \theta
$$

The pseudo-spectral acceleration corresponding to the combined time series is:

$$
P S A_{c m b}(T, \zeta, \theta)=\omega^{2} \max _{t}\left(\left|u_{c m b}(t, \theta)\right|\right)
$$

RotD50 is the median pseudo-spectral acceleration over all rotation angles:

$$
\operatorname{RotD50}(T, \zeta)=\operatorname{median}_{\theta}\left\{P S A_{c m b}(T, \zeta, \theta)\right\}
$$

and RotD100 is the maximum pseudo-spectral acceleration over all rotation angles:

$$
\operatorname{RotD} 100(T, \zeta)=\max _{\theta}\left\{P S A_{c m b}(T, \zeta, \theta)\right\}
$$

In the following, we show that SA (Equation 1) and RotD100 (Equation 10) are equivalent intensity measures and that their orientation is the same. From Equations 10 and 7, we get:

$$
\begin{aligned}
\operatorname{RotD}_{100} & =\omega^{2} \max _{\theta}\left\{\max _{t}\left\{\left|u_{x}(t) \cos \theta+u_{y}(t) \sin \theta\right|\right\}\right\} \\
& =\omega^{2} \max _{t}\left\{\max _{\theta}\left\{\left|u_{x}(t) \cos \theta+u_{y}(t) \sin \theta\right|\right\}\right\}
\end{aligned}
$$

The non-redundant rotations involve $\theta \in\left[0,180^{\circ}\right]$. Let $u_{x}(t)=r(t) \cos \psi(t)$ and $u_{y}(t)=r(t) \sin \psi(t)$. Then $r(t)=\left(u_{x}^{2}(t)+u_{y}^{2}(t)\right)^{1 / 2}$ and $\psi(t)=\arctan \left(\left(u_{y}(t)\right) /\left(u_{x}(t)\right)\right)$. Thus, we get:

$$
\begin{aligned}
\left|u_{x}(t) \cos \theta+u_{y}(t) \sin \theta\right| & =|r(t)(\cos \psi(t) \cos \theta+\sin \psi(t) \sin \theta)| \\
& =r(t)|\cos (\theta-\psi(t))| \leqslant r(t)
\end{aligned}
$$

Since $\theta \in\left[0,180^{\circ}\right]$, for each time $t$ there exists a rotation angle $\theta(t)$ for which $|\cos (\theta(t)-\psi(t))|=1$ which occurs for:

$$
\theta(t)=\psi(t)=\arctan \left(\frac{u_{y}(t)}{u_{x}(t)}\right)
$$


and gives:

$$
\max _{\theta}\left|u_{x}(t) \cos \theta(t)+u_{y}(t) \sin \theta(t)\right|=r(t)=\left(u_{x}^{2}(t)+u_{y}^{2}(t)\right)^{1 / 2}
$$

Thus, from Equation $11 \mathrm{~b}$ after maximizing with respect to $\theta$ we get:

$$
\operatorname{RotD} 100=\omega^{2} \max _{t}\left\{\left(u_{x}(t)^{2}+u_{y}(t)^{2}\right)^{1 / 2}\right\}
$$

which is exactly the same as the $S A$ measure defined in Equation 1. Furthermore, the time $t_{m}$ at which this maximum occurs corresponds to rotation angle $\theta\left(t_{m}\right)$ given by Equation 13 with $t$ replaced by $t_{m}$, and thus corresponds to the angle $\varphi$ defined by Equation 2 for the $S A$ measure. 